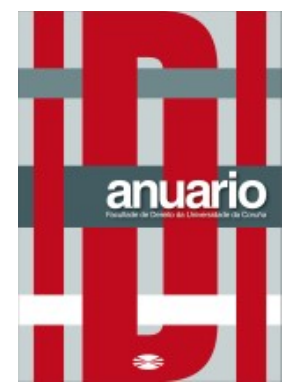

Anuario da Facultade de Dereito da Universidade da Coruña

Vol. 23 (2019), pp. 339-372

ISSNe: 2530-6324 || ISSN: 1138-039X

DOI: https://doi.org/10.17979/afdudc.2019.23.0.6022

\title{
LOS CONTRATOS DE TELEASISTENCIA EN LA DOCTRINA DE LOS TRIBUNALES ADMINISTRATIVOS DE CONTRATACIÓN
}

\section{THE TELECARE CONTRACTS IN THE DOCTRINE OF THE ADMINISTRATIVE PROCUREMENT TRIBUNALS}

\author{
MARÍA DEL CARMEN RODRÍGUEZ MARTÍN-RETORTILLO \\ Profesora interina de Derecho Administrativo e Investigadora \\ Universidade da Coruña
}

Resumen: En este artículo se analizan distintos supuestos planteados ante los tribunales administrativos de contratación en el ámbito de los contratos de teleasistencia, profundizando en su argumentación y exponiéndolos de forma sistemática.

Palabras clave: contratos, teleasistencia, recursos, Tribunales administrativos de contratación, servicio.

Resumo: Neste artigo analízanse distintos supostos plantexados ante os tribunais administrativos de contratación no ámbito dos contratos de teleasistencia, profundizando na súa argumentación e expoñéndoos de forma sistemática.

Palabras chave: contratos, teleasistencia, recursos, Tribunais administrativos de contratación, servizo.

Abstract: In this article, different assumptions raised before the Administrative Procurement Tribunals in the field of telecare contracts are analyzed, deepening their arguments and exposing them systematically.

Keywords: contracts, telecare, resources, Administrative Procurement Tribunals, service.

Sumario: I. INTRODUCCIÓN. II. LEGITIMACIÓN. III. FALTA DE DIVISIÓN EN LOTES. IV. ARRAIGO TERRITORIAL. 1. Arraigo territorial admisible. 2. Arraigo territorial no admisible. V. REQUISITO DE SOLVENCIA. EXPERIENCIA EN LA PRESTACIÓN DE UN SERVICIO DE TELEASISTENCIA EN EL QUE SE HAYAN GESTIONADO SIMULTÁNEAMENTE COMO MÍNIMO 20.000 TERMINALES ACTIVOS. VI. PRESUPUESTO BASE DE LICITACIÓN. INVIABILIDAD ECONÓMICA. VII. 
CRITERIOS DE ADJUDICACIÓN. 1. Mayor número de centrales de respaldo en territorio nacional. Límite máximo. A. Mayor número de centrales. B. Límite máximo de unidades. 2. Mayor número de unidades móviles en la provincia. 3. Prestación de servicios complementarios. 4. Plan de formación. VIII. SUBROGACIÓN DE TRABAJADORES. 1. Inclusión en pliegos de una cláusula en virtud de la cual se impone al adjudicatario la subrogación de los trabajadores adscritos al servicio. 2. Exigir que dicha subrogación se produzca antes de la firma del contrato y como condición esencial al mismo. A. Precio en atención a las obligaciones de subrogación. B. Considerar el contrato económicamente inviable atendidos los gastos de personal a subrogar que constan en la documentación de la licitación. IX. EXCLUSIÓN DE OFERTA POR SUPERAR EL TIPO DE LICITACIÓN. SOLICITUD DE ACLARACIONES. X. INSUFICIENCIA DE INFORMACIÓN A LOS LICITADORES. XI. FÓRMULA DE PROPORCIONALIDAD. XII. EXCLUSIÓN DE OFERTA DE TELEASISTENCIA POR ANORMALMENTE BAJA. XIII. CONFIDENCIALIDAD DE LA JUSTIFICACIÓN DE LAS BAJAS. XIV. SUBSANACIÓN EN FASE DE REQUERIMIENTO. XV. CONCLUSIONES. XVI. BIBLIOGRAFÍA.

\section{INTRODUCCIÓN}

Desde el punto de vista normativo, el Art. 22 de la Ley 39/2006, de 14 de diciembre, de Promoción de la Autonomía Personal y Atención a las personas en situación de dependencia, delimita el concepto de teleasistencia ${ }^{1}$. Este precepto ha sido desarrollado mediante acuerdo del Consejo Territorial de Servicios Sociales y del Sistema para la Autonomía y Atención a la Dependencia, que define el servicio de teleasistencia básica, indicando que consiste en facilitar asistencia a las personas beneficiarias de forma ininterrumpida, mediante el uso de la tecnología de la información y de la comunicación, con apoyo de los medios personales necesarios, en respuesta inmediata ante situaciones de emergencia, de inseguridad, soledad y aislamiento. Se lleva a cabo a través de la instalación de un terminal en la vivienda de la persona beneficiaria conectado a una central receptora, con la que se comunica en caso de urgencia mediante la activación de un pulsador ${ }^{2}$.

La teleasistencia avanzada es aquella que incluye además de los servicios de teleasistencia básica que la persona usuaria precise, apoyos tecnológicos complementarios dentro o fuera del domicilio, o en ambos casos, así como la interconexión con los servicios de información y profesionales de referencia en los

\footnotetext{
1 Art. 22: "1. El servicio de Teleasistencia facilita asistencia a los beneficiarios mediante el uso de tecnologías de la comunicación y de la información, con apoyo de los medios personales necesarios, en respuesta inmediata ante situaciones de emergencia, o de inseguridad, soledad y aislamiento. Puede ser un servicio independiente o complementario al de ayuda a domicilio".

${ }^{2}$ Resolución de 15 de enero de 2018, de la Secretaría de Estado de Servicios Sociales e Igualdad, por la que se publica el Acuerdo del Consejo Territorial de Servicios Sociales y del Sistema para la Autonomía y Atención a la Dependencia, sobre determinación del contenido del servicio de teleasistencia básica y avanzada (BOE nº41, de 15 de febrero de 2018).
} 
sistemas sanitario y social, desarrollando procesos y protocolos de actuación en función de la situación de necesidad de atención detectada.

Por su parte, los pliegos de cláusulas administrativas han definido igualmente qué se entiende por Teleasistencia Domiciliaria, señalando que "es un servicio que, a través de la línea telefónica y con un equipamiento de comunicaciones e informático específico ubicado en un Centro de Atención y en el domicilio de los usuarios, permite a las personas mayores y/o personas discapacitadas, con solo pulsar el botón que llevan constantemente y sin molestias, entrar en contacto verbal "manos libres" durante las 24 horas del día y los 365 días del año, con un centro atendido por personal específicamente preparado para dar respuesta inmediata y adecuada a la situación de emergencia, inseguridad, soledad,... presentada, bien por sí mismo o movilizando otros recursos humanos o materiales, propios del usuario o existentes en la comunidad.

Este servicio se complementa con "agendas de usuario" que permiten recordar a la persona beneficiaria del servicio la necesidad de realizar una actividad concreta en un momento determinado, de forma esporádica o con la periodicidad que se fije, como por ejemplo, la toma de medicamentos, la realización de una gestión, etc."3. Para prestar este servicio tan esencial las Administraciones recurren a la contratación púbica para que entidades o empresas especializadas cubran estas necesidades.

En este trabajo se exponen los aspectos más controvertidos de los contratos de teleasistencia que han sido resueltos por los Tribunales Administrativos de Contratación sistematizando su tratamiento a través de un análisis temático donde se contiene la doctrina sobre cuestiones concretas que han sido planteadas ante los mismos tratando problemática relacionada con la legitimación, la falta de división en lotes, el arraigo territorial, el requisito de solvencia, el presupuesto base de licitación, los criterios de adjudicación, la subrogación de trabajadores, la exclusión de la oferta por superar el tipo de licitación, la insuficiencia de información a los licitadores, la fórmula de proporcionalidad, la exclusión de la oferta por anormalmente baja, la confidencialidad de la justificación de las bajas y la subsanación en fase de requerimiento para terminar con unas conclusiones a modo de cierre y las referencias bibliográficas.

\section{LEGITIMACIÓN}

El Art. 48 de la Ley 9/2017, de 8 de noviembre, de Contratos del Sector Público, por la que se transponen al ordenamiento jurídico español las Directivas del Parlamento Europeo y del Consejo 2014/23/UE y 2014/24/UE, de 26 de febrero de 2014 (en adelante, LCSP) introduce dos novedades respecto al Art. 42 del Real Decreto Legislativo 3/2011, de 14 de noviembre, por el que se aprueba el texto refundido de la Ley de Contratos del Sector Público (en adelante, TRLCSP) ${ }^{4}$.

Por un lado, amplía el ámbito de la legitimación no ya únicamente a aquellos que resulten perjudicados en sus derechos e intereses legítimos (tal y como disponía el TRLCSP) sino que se especifica que tales derechos e intereses legítimos pueden ser

\footnotetext{
${ }^{3}$ Definido así en el Pliego de Prescripciones Técnicas (Cláusula 2) del contrato de prestación del servicio de teleasistencia domiciliaria en el municipio de Laredo, citada por la Resolución n406/2019 del TACRC.

${ }^{4}$ Como se ha resuelto por el Tribunal Administrativo Central de Recursos Contractuales (en adelante, TACRC), entre otras, en la Resolución nº1050/2018.
} 
"individuales o colectivos" y, además, se abre a la afectación indirecta "puedan resultar afectados, de manera directa o indirecta por las decisiones objeto del recurso".

Y, por otro lado, el párrafo segundo del Art. 48 de la LCSP legitima a las organizaciones sindicales para interponer este recurso cuando de las decisiones recurribles se pudiera deducir fundadamente que estas implican que en el proceso de ejecución del contrato se incumplirán las obligaciones sociales o laborales respecto de los trabajadores que participen en la realización de la prestación, con la contrapartida de que también lo estará "la organización empresarial sectorial representativa de los intereses afectados".

El tenor de dicho precepto, así como la doctrina del TACRC, conduce a entender que la legitimación de los sindicatos y asociaciones empresariales únicamente será admisible si los motivos de impugnación tienen una relación directa e incuestionable con la defensa de los intereses colectivos, sin que pueda admitirse dicha legitimación en el supuesto de que los motivos del recurso rebasen este ámbito o se refieran a cuestiones de legalidad ordinaria de los pliegos o el procedimiento.

En el recurso analizado, la recurrente no invoca un interés colectivo de las empresas asociadas, distinto del interés propio de las empresas participantes, que no han recurrido la adjudicación, o de un mero interés por la legalidad, que no es título de legitimación ${ }^{5}$.

\section{FALTA DE DIVISIÓN EN LOTES}

Los Considerandos 78 y 79 y el Art. 46 de la Directiva 2014/24 promueven la división del contrato en lotes ${ }^{6}$. La LCSP en su Art. 99 lo regula, estableciendo que se debe justificar la no división en lotes ${ }^{7}$.

\footnotetext{
${ }^{5}$ Resolución n ${ }^{\circ} 60 / 2019$ del TACRC, de 24 de enero de 2019.

${ }^{6}$ Debe adaptarse la contratación pública a las necesidades de las PYME. Es preciso alentar a los poderes adjudicadores a utilizar el código de mejores prácticas que se establece en el documento de trabajo de los servicios de la Comisión, de 25 de junio de 2008, titulado "Código europeo de buenas prácticas para facilitar el acceso de las PYME a los contratos públicos", que ofrece orientaciones acerca de cómo aplicar el régimen de contratación pública de forma que se facilite la participación de las PYME. A tal efecto y para aumentar la competencia, procede animar a los poderes adjudicadores a, en particular, dividir grandes contratos en lotes. Esta división podría realizarse de manera cuantitativa, haciendo que la magnitud de cada contrato corresponda mejor a la capacidad de las PYME, o de manera cualitativa, de acuerdo con los diferentes gremios y especializaciones implicados, para adaptar mejor el contenido de cada contrato a los sectores especializados de las PYME o de acuerdo con las diferentes fases ulteriores de los proyectos.

La magnitud y el contenido de los lotes deben ser determinados libremente por el poder adjudicador, el cual, de acuerdo con las normas pertinentes en materia de cálculo del valor estimado de la contratación, debe estar autorizado a adjudicar algunos de los lotes sin aplicar los procedimientos previstos en la presente Directiva. El poder adjudicador debe estar obligado a estudiar la conveniencia de dividir los contratos en lotes, sin dejar de gozar de la libertad de decidir de forma autónoma y basándose en las razones que estime oportunas, sin estar sujeto a supervisión administrativa o judicial. Cuando el poder adjudicador decida que no sería conveniente dividir el contrato en lotes, el informe específico o los pliegos de la contratación deben incluir una indicación de las principales razones que expliquen la elección hecha por el poder adjudicador. Estas razones podrían ser, por ejemplo, el hecho de que el poder adjudicador considere que dicha división podría conllevar el riesgo de restringir la competencia, o hacer la ejecución del contrato excesivamente difícil u onerosa desde el punto de vista técnico, o que la necesidad de coordinar a los diferentes contratistas para los diversos lotes podría conllevar gravemente el riesgo de socavar la ejecución adecuada del contrato.
} 
El recurrente alega la no conformidad a derecho de la falta de división en lotes, dado que, por un lado no se justifica suficientemente dicha división, con arreglo a lo dispuesto en el Art. 99 de la LCSP y, en todo caso, no se encuentra justificación alguna a la no división en función de áreas geográficas, especialmente teniendo en cuenta que es el pliego de prescripciones técnicas (en adelante, PPT) el que establece la división provincial como ámbito propio de prestación del servicio, dado que la ejecución del contrato se apoya precisamente en las Direcciones Provinciales ${ }^{8}$.

\section{El Tribunal alega:}

a) La obligación de dividir en lotes tiene una finalidad específica, que es promover la concurrencia de las PYMES en los contratos del sector público.

b) Esa obligación se encuentra especialmente justificada cuando se licitan grandes contratos.

c) El órgano de contratación debe ser libre de decidir de forma autónoma y basándose en las razones que estime oportunas la magnitud de cada expediente y de cada lote.

d) En caso de que se decida no dividir en lotes, deben indicarse las principales razones que expliquen la elección hecha por el poder adjudicador.

e) Los motivos válidos a que se refiere el artículo 99 son de carácter enunciativo, pudiendo existir otros.

Partiendo de lo anterior, el Tribunal ha venido aplicando una doctrina en torno al margen de discrecionalidad de que gozan los órganos de contratación a la hora de definir el objeto del contrato y su división en lotes, así como qué motivos se consideran válidos para que el órgano de contratación decida la no división en lotes ${ }^{9}$.

Los Estados miembros deber seguir gozando de libertad para prolongar sus esfuerzos tendentes a facilitar la participación de las PYME en el mercado de la contratación pública, ampliando el alcance de la obligación de considerar la conveniencia de dividir los contratos en lotes convirtiéndolos en contratos más pequeños, exigiendo a los poderes adjudicadores que aporten una justificación de la decisión de no dividir los contratos en lotes o haciendo obligatoria la división en lotes bajo ciertas condiciones. A este mismo respecto, los Estados miembros deben gozar también de la libertad de facilitar mecanismos para efectuar pagos directos a los subcontratistas

7 “Código europeo de buenas prácticas para facilitar el acceso de las PYME a los contratos públicos".

${ }^{8}$ Resolución n ${ }^{\circ} 993 / 2018$ del TACRC, de 2 de noviembre de 2018.

9 Así, la Resolución nº430/2018 del TACRC señala que "la discrecionalidad de los órganos de contratación para determinar si las prestaciones objeto del contrato constituyen una unidad contractual o no, así como si son susceptibles de unidades fundacionales independientes divisibles en lotes, se manifiesta bajo el prisma de la racionalización de la contratación administrativa. En este sentido, la doctrina de los Tribunales de recursos contractuales, partiendo de la literalidad del artículo 86.3 del TRLCSP, que configura el fraccionamiento del contrato como una facultad o derecho potestativo que asiste al órgano de contratación, expresan que se trata de una decisión que entraña un indudable componente de discrecionalidad técnica en función de las concretas circunstancias que en cada caso concurran. Al respecto, en nuestra Resolución $n^{\circ} 408 / 2017$-citada posteriormente en la $n^{\circ} 600 / 2017$ hemos señalado lo siguiente: "En relación con la previsión de este artículo 46 de la Directiva, este Tribunal ha declarado, entre otras, en la resolución 814/2016, que del mismo se desprende que "la división no es obligatoria", siendo así que, por mucho que el considerando 78 de la Directiva 2014/24/UE exprese que, para aumentar la competencia, "procede animar a los poderes adjudicadores a, en particular, dividir grandes contratos en lotes", también añade que tales poderes adjudicadores deben conservar "la libertad de decidir de forma autónoma y basándose en las razones que estime oportunas, sin estar sujeto a supervisión administrativa o judicial", exigiendo únicamente que se estudie la conveniencia de tal división, a cuyo fin, "cuando el poder adjudicador decida que no sería conveniente dividir el 
En definitiva, el órgano de contratación goza de un amplio margen de discrecionalidad para determinar el objeto del contrato y su división o no en lotes, margen que está sujeto también a la doctrina de la discrecionalidad técnica, debiendo, eso sí, explicar las razones principales por las cuales decide que no procede dicha división, razones que han de atender a un motivo válido, es decir, que no resulte arbitrario ni contrario a la finalidad última del precepto, esto es, la concurrencia de las PYMES.

En este sentido, es cierto que la justificación que ha de ofrecer el órgano de contratación, si bien no tiene que ser necesariamente exhaustiva, debe referirse a las concretas razones que concurren en ese expediente, sin que sea admisible la mera formulación del propio precepto para considerar cumplida esta obligación. Por otra parte, habrán de tenerse en cuenta las circunstancias concurrentes en cada expediente para poder determinar si la justificación ofrecida por el órgano de contratación es suficientemente expresiva de dichas razones o no, único elemento al que podría en su caso alcanzar la revisión de este Tribunal que, por lo demás, tiene vedada la supervisión de la corrección técnica de dicha decisión, en virtud de la doctrina de la discrecionalidad técnica, que resulta aplicable a este caso.

En este supuesto, en el cuadro de características de los pliegos las razones para la no división en lotes son escuetas, limitándose a un párrafo genérico, y analizada la documentación de la licitación y los pliegos en su conjunto, debe darse la razón al órgano de contratación al concurrir motivos válidos en este caso, justificados en el expediente, que permiten no dividir el contrato en lotes:

a) El servicio de asistencia domiciliaria, como servicio público requiere asegurar el cumplimiento de los principios de igualdad, universalidad, regularidad y accesibilidad, lo que, a juicio del órgano de contratación, puede conseguirse técnicamente mejor mediante la prestación del servicio de forma conjunta en todo el territorio.

b) En particular, en relación con la alegación relativa a la posibilidad de dividir en lotes por provincia, se observa en el PPT que el apoyo que prestan las Direcciones Provinciales en la ejecución del servicio es accesorio o de apoyo, que tiene que ver fundamentalmente con tareas de registro de altas y bajas o atención de incidencias. Sin embargo, en el PPT se establece la coordinación y distribución de tareas a nivel regional; estableciéndose la obligación de contar con un Responsable Regional y un Director del Centro de Atención que aseguran el correcto funcionamiento del servicio en todo el territorio.

\section{ARRAIGO TERRITORIAL}

A continuación, se analizan dos resoluciones relativas al arraigo territorial, que mantienen diferentes criterios.

\section{Arraigo territorial admisible}

contrato en lotes, el informe especifico o los pliegos de la contratación debe incluir una indicación de las principales razones que expliquen la elección hecha por el poder adjudicador". 
Ha sido un criterio unánime de los Tribunales de contratación que la condición de arraigo territorial no pueda ser exigida como requisito de solvencia, ni como criterio de adjudicación, sin embargo, como condición de ejecución se ha admitido en determinadas ocasiones.

Así se pretende la anulación de una cláusula del Pliego Prescripciones Técnicas, en la medida en que exige como recurso técnico la existencia de un centro de atención en la Comunidad de Cantabria ${ }^{10}$, estimando el recurrente que se trata de una condición de arraigo territorial que no puede ser exigida a los licitadores ${ }^{11}$. El adjudicatario solicita la desestimación del recurso presentado considerando que el mentado centro de atención no constituye ninguna condición de arraigo territorial proscrita, ya que no se exige como un requisito para participar en la licitación ni como criterio de adjudicación, sino como un requisito a cumplir por el adjudicatario, existiendo razones objetivas, debidas a las características del servicio, que justifican su exigencia.

En este caso, debemos analizar en qué concepto se exige el requisito técnico consistente en la ubicación del Centro de Atención en la Comunidad de Cantabria, si como un requisito exigible a todos los licitadores como criterio de solvencia ${ }^{12}$ o de adjudicación, o si se hace como un compromiso de solvencia adicional o una condición de ejecución exigible únicamente al adjudicatario ${ }^{13}$. Si bien no es correcto afirmar que la exigencia de la ubicación del Centro de Atención en la Comunidad de Cantabria se configure como un compromiso de adscripción de medios, en los términos del Art. 76.2 LCSP (pues los Pliegos señalan expresamente que no se exigirá tal compromiso en su Cláusula 16 y en el apartado 12 de Anexo I), sí es cierto que no es un requisito exigible a todos los licitadores (ya sea como requisito de solvencia o como criterio de adjudicación), sino de una obligación impuesta al adjudicatario (sin el carácter de esencial), cuyo incumplimiento podría dar lugar a la imposición de penalidades.

Por lo tanto, las propias características del servicio justifican la necesidad de que el Centro de Atención se ubique en la Comunidad Autónoma de Cantabria, resultando ese requisito plenamente proporcionado y respetuoso con los principios de libre concurrencia e igualdad de trato, en los mismos términos en que así se ha considerado por las múltiples resoluciones dictadas por este Tribunal, como son, entre otras, la n $546 / 2018$, de 1 de junio de 2018; la n³28/2018, de 6 de abril de 2018; o la $n^{\circ} 621 / 2015$, de 6 de julio (Rec. 546/2015). En particular, en esta última, que resuelve un caso similar en Cantabria, se cita la Resolución $\mathrm{n}^{0} 515 / 2013$, de 14 de noviembre

\footnotetext{
${ }^{10}$ Resolución n406/2019 del TACRC, de 17 de abril de 2019.

${ }^{11}$ Resoluciones del TACRC n⿳5526/2013, de 15 de noviembre; 217/2012, de 3 de octubre; 138/2011 y 139/2011, de 11 de mayo; Resolución 29/2011, de 9 de febrero. En igual sentido, la Junta Consultiva de Contratación Administrativa (Informe 9/2009, de 31 de marzo), y el Art. 18.2.a) de la Ley 20/2013, de 9 de diciembre, de Garantía de la Unidad de Mercado.

${ }^{12}$ La "Guía sobre contratación pública y competencia” de la Comisión Nacional de la Competencia, de 27 de abril de 2010, recoge la prohibición de exigir como criterio de solvencia la ubicación de instalaciones de los posibles adjudicatarios en el territorio en el que se tenga que ejecutar el contrato, por ser una previsión contraria a la competencia y al principio de no discriminación e igualdad de trato.

${ }^{13}$ Resolución n406/2019 del TACRC, de 17 de abril de 2019.
} 
(Recurso 687/2013) ${ }^{14}$. La Resolución no546/2018, de 1 de junio, del TACRC se pronuncia en igual sentido ${ }^{15}$.

\section{Arraigo territorial no admisible}

En la resolución del Tribunal Administrativo de Recursos Contractuales de Castilla y León analizada sobre este tema ${ }^{16}$, la recurrente mantiene que en los pliegos se produce una discriminación por razón de la territorialidad.

La Cláusula 8.1 del PPT estipula que, entre los recursos necesarios para proporcionar la gestión y ejecución del servicio, la empresa adjudicataria deberá contar con el de una central de atención ubicada específicamente en Castilla y León.

La empresa recurrente considera que "no es necesario, ni incide en modo alguno, que el centro de atención se ubique en Castilla y León, no conteniendo tampoco el pliego, ninguna explicación de las necesidades que, de cara a la prestación del servicio objeto de contrato, se pretenden satisfacer con el referido criterio territorial".

Al respecto este Tribunal considera que el servicio de teleasistencia puede ser prestado de forma telemática, por lo que este requisito no guarda vinculación directa con el objeto del contrato y que, además, no se justifica en el expediente qué beneficio podría tener la localización para la prestación del servicio ${ }^{17}$.

Por ello, la previsión contenida en el PPT determina no solo la nulidad de la cláusula 8.1 que da origen al recurso al posibilitar un trato discriminatorio, sino también la de la licitación misma, por cuanto, con la anulación del medio material exigido en cuestión, se estarían modificando las condiciones del contrato con vulneración de los principios de transparencia e igualdad de trato entre todos los licitadores, tanto los concurrentes como terceros que habrían podido presentarse a dicha licitación. En

\footnotetext{
14 "De acuerdo con lo anteriormente expuesto, la exigencia del "Centro de Atención de Teleasistencia" exigible al adjudicatario del contrato como compromiso de adscripción de medios tanto en el PCAP como en el PPT, no vulnera la normativa expuesta ni colisiona con los principios de libertad de empresa y concurrencia competitiva, pues es una obligación exigible únicamente a la empresa adjudicataria".

15 "El servicio de teleasistencia a contratar tiene una serie de singularidades derivadas de las circunstancias personales de sus destinatarios (octogenarios, personas en situación de vulnerabilidad social o diversidad funcional) que exigen un profundo conocimiento del entorno sanitario, social y cultural en el que se desenvuelven los destinatarios". Así, "dada la singularidad de los destinatarios parece razonable y proporcionado que se exija una vinculación con el territorio en el que va a desempeñarse la función", "resulta evidente que el servicio que constituye el objeto del contrato va más allá de lo que es un servicio de teleasistencia genérico, pues la implicación con la vida y las necesidades de los usuarios justifican una implantación en el espacio en el que residen estos, de tal manera que por mucho que los medios no exijan materialmente la presencia física el objetivo a satisfacer sí implica una imbricación social".

${ }^{16}$ Resolución n46/2019 del Tribunal Administrativo de Recursos Contractuales de Castilla y León, de 17 de abril.

${ }^{17}$ Como ha señalado este Tribunal (por todas, las Resoluciones 5/2013, de 29 de agosto; 30/2016, de 5 de mayo; 75/2016, de 8 de noviembre; 18/2018, de 22 de febrero; y 28/2019, de 14 de marzo) la doctrina es pacífica al considerar que los criterios de arraigo territorial no pueden ser ni requisitos de solvencia ni criterios de adjudicación. Son admisibles, por el contrario, cuando se configuran como compromiso de adscripción de medios (artículo 76.2 de la LCSP) o como condición de ejecución del contrato en el pliego técnico, siempre que se ajusten al principio de proporcionalidad, atendida su relación con el objeto y el importe del contrato, y respeten los principios de concurrencia, igualdad y no discriminación que rigen la contratación pública.
} 
consecuencia, procede estimar el recurso especial en materia de contratación interpuesto.

\section{REQUISITO DE SOLVENCIA. EXPERIENCIA EN LA PRESTACIÓN DE UN SERVICIO DE TELEASISTENCIA EN EL QUE SE HAYAN GESTIONADO SIMULTÁNEAMENTE COMO MÍNIMO 20.000 TERMINALES ACTIVOS}

En la resolución del TACRC que se refiere a esta cuestión ${ }^{18}$, el recurrente alega la no conformidad a derecho por ser contrario al principio de concurrencia de la exigencia como criterio de solvencia la presentación de, al menos, un certificado de buena ejecución que acredite "experiencia en la prestación de un servicio de teleasistencia en el que se hayan gestionado simultáneamente como mínimo 20.000 terminales activos".

Además, considera que en este caso el hecho de que se hayan operado un número determinado de terminales no acredita una mayor experiencia en cuanto a la complejidad técnica en la ejecución del contrato, sino solamente una mayor disponibilidad de medios personales y materiales.

"A la vista de dicho precepto, (artículo 90.1 a) de la LCSP), debe concluirse que en estos casos los pliegos pueden, sin ninguna duda, establecer requisitos adicionales que permitan concretar la experiencia, conocimientos y medios en las concretas materias a que se refiera la contratación, siendo además lícito, tal y como ha señalado la doctrina de este Tribunal, que dichos requisitos adicionales permitan garantizar que la experiencia demostrada por el licitador se refiere a servicios verdaderamente similares por razón del tipo de las prestaciones a realizar, por indicación de alguna o algunas de sus características, sin que pueda referirse a las cualidades de la entidad" (Resolución nº438/2017).

Además, para la determinación de tales criterios el órgano de contratación goza de un amplio margen de discrecionalidad, basado en la doctrina de la discrecionalidad técnica, lo que limita el alcance de la revisión que tiene que llevar a cabo este Tribunal, que solo puede versar sobre:

i) aspectos formales de la valoración (competencia o procedimiento) y

ii) si se ha incurrido en discriminación.

Ahora bien, ello no significa que el órgano de contratación pueda establecer requisitos de forma arbitraria o desproporcionada, sino que habrán de i) estar vinculados a lo que sea objeto de la contratación, ii) ser proporcionados a lo que es objeto de la contratación y iii) no ser discriminatorios, en el sentido de ser tan exigentes que de facto solo determinadas empresas puedan cumplir con los mismos, sin que exista justificación suficiente para ello.

Pues bien, en el presente caso, nos encontramos ante un contrato cuyo objeto es el servicio de teleasistencia. Según se describe en el PPT (apartado 2.1 segundo párrafo):

\footnotetext{
${ }^{18}$ Resolución nº93/2018 del TACRC, de 2 de noviembre de 2018.
} 
"La teleasistencia se presta fundamentalmente a través de comunicación telefónica, pero también incluye visitas domiciliarias y actividades comunitarias de promoción del envejecimiento activo. Permite comunicarse durante las 24 horas y los 365 días al año, asegurando una atención permanente y ofreciendo respuesta inmediata ante determinadas eventualidades. El Servicio de Teleasistencia de Castilla-La Mancha es un servicio sin custodia de llaves, basado en la disponibilidad de personas de contacto con llave del domicilio".

En el PPT se señala además (Apartado 4, Tabla E) el número de terminales domiciliarios y personas usuarias previstas a 31 de diciembre, habiéndose previsto un número de terminales en 2019 de 45.000 y alrededor de 56.000 personas usuarias, pasando en 2023 a 57.000 terminales y algo más de 71.000 personas usuarias.

Por ello, si en el PPT se indica que la prestación del servicio se efectúa fundamentalmente a través de comunicación telefónica no parece que sea arbitrario ni ajeno al objeto contractual definir los servicios similares en atención al número de terminales operador en otros servicios, pues es una forma de describir la dimensión del servicio que es objetiva, evitando entrar en otras características subjetivas de difícil calificación en esta fase del procedimiento de licitación. En definitiva, para asegurar la correcta prestación del servicio, se exige acreditar experiencia en un servicio de características similares, utilizando el parámetro del número de terminales como el parámetro objetivo que permite obtener esa similitud, lo que no se considera arbitrario.

Por otra parte, el número de terminales que se indica como umbral para la acreditación de la solvencia es de 20.000 , esto es, menos de la mitad de los que se encuentran actualmente en operación, por lo que también cabe afirmar su proporcionalidad.

Tampoco se puede considerar que se trate de un criterio discriminatorio, porque no se ha justificado por la recurrente que solo pueda ser cumplido por empresas determinadas. Debe darse la razón al órgano de contratación en el sentido de que el razonamiento lógico plasmado en el escrito del recurrente según el cual se estaría exigiendo acreditar haber prestado servicios de más de un millón de usuarios, resulta totalmente injustificado, teniendo en cuenta que en este caso la relación es de menos de 1,3 usuarios por terminal, según se deduce de la tabla antes mencionada y especialmente teniendo en cuenta, como dice el órgano de contratación, la posibilidad de integrar la solvencia exigida con medios externos.

Por tanto, el criterio de solvencia impugnado se considera conforme a Derecho, por lo que no debe ser acogido el recurso en este punto.

\section{PRESUPUESTO BASE DE LICITACIÓN. INVIABILIDAD ECONÓMICA}

La resolución de referencia en este tema es la Resolución n46/2019 del Tribunal Administrativo de Recursos Contractuales de Castilla y León ${ }^{19}$, donde la recurrente considera que el contrato, tal y como está planteado, es inviable económicamente $^{20}$, ya que únicamente con el personal a subrogar establecido en el

\footnotetext{
${ }^{19}$ Resolución nº6/2019 del Tribunal Administrativo de Recursos Contractuales de Castilla y León, de 17 de abril.

${ }^{20}$ Ibidem.
} 
pliego y con los datos contractuales que se reflejan se observa que el coste anual para la empresa que resulte adjudicataria ascendería a 294.967 euros, cantidad ya, en sí misma, superior a los ingresos que se generarían del contrato y que ascenderían a 188.392, teniendo en cuenta que el servicio debe prestarse a 988 usuarios con un precio de licitación de 15,89 euros.

Añade que el coste mínimo anual de personal, considerando además el resto de los costes asociados que se producen con el desarrollo de esta actividad, como los costes de instalaciones, equipo informático, móviles, uniformes, formación, kilometraje, comunicaciones, amortizaciones, sede u oficina y demás gastos en los que se incurren este tipo de servicios, no se ven cubiertos con el presupuesto de licitación.

No obstante, en la Resolución n⿳5十/2016, del Tribunal Administrativo de Recursos Contractuales de Castilla y León (recurso 42/2016), de 4 de agosto, dictada bajo la vigencia dela normativa anterior, se consideró que los argumentos esgrimidos en el recurso resultaban suficientes para desvirtuar el fundamento de la decisión adoptada por el órgano de contratación en relación con la imposibilidad de cumplimiento normal de la oferta de la recurrente, en la medida en que, basada su exclusión exclusivamente en el informe técnico del economista municipal de 8 de febrero de 2016, éste, en el informe de 22 de julio de 2016, señaló que en el primero no se indica realmente que la oferta no pueda ser cumplida, ni se negó la viabilidad de los costes e ingresos. Por el contrario, basó la viabilidad económica del servicio a prestar en economías de escala o sinergia empresarial, es decir, en la solvencia de la propia empresa, lo cual no contradice las prescripciones que la Ley establecía en orden al modo de justificar la viabilidad de la oferta y la posibilidad de ejecutar el contrato. Debe tenerse presente que las normas sobre temeridad no imponen de manera absoluta la necesidad de valorar la congruencia económica de la oferta en sí misma, sino si es viable que la empresa licitadora la ejecute.

Para analizar actualmente el supuesto examinado, es preciso tener en cuenta que la actual LCSP supone un importante cambio en la configuración del presupuesto base de licitación y determinación del valor estimado del contrato, con una mayor sujeción a la normativa laboral, como pone de relieve la Resolución 37/2019, del Tribunal Administrativo de Recursos Contractuales de Castilla y León, de 4 de abril.

El Art. 100.2, inciso segundo, de la LCSP, respecto del presupuesto base de licitación, dispone que "en los contratos en que el coste de los salarios de las personas empleadas para su ejecución forme parte del precio total del contrato, el presupuesto base de licitación indicará de forma desglosada y con desagregación de género y categoría profesional los costes salariales estimados a partir del convenio laboral de referencia".

El Art. 101.2 de la LCSP, al referirse al valor estimado del contrato, establece que "en el cálculo del valor estimado deberán tenerse en cuenta, como mínimo, además de los costes derivados de la aplicación de las normativas laborales vigentes, otros costes que se deriven de la ejecución material de los servicios, los gastos generales de estructura y el beneficio industrial. (...) 
En los contratos de servicios y de concesión de servicios en los que sea relevante la mano de obra, en la aplicación de la normativa laboral vigente a que se refiere el párrafo anterior se tendrán especialmente en cuenta los costes laborales derivados de los convenios colectivos sectoriales de aplicación".

Respecto del precio, el Art. 102.3 de la LCSP señala que "los órganos de contratación cuidarán de que el precio sea adecuado para el efectivo cumplimiento del contrato mediante la correcta estimación de su importe, atendiendo al precio general de mercado, en el momento de fijar el presupuesto base de licitación y la aplicación, de ser el caso, de las normas sobre ofertas con valores anormales o desproporcionados.

En aquellos servicios en que el coste económico principal sean los costes laborales, se deberán considerar los términos económicos de los convenios colectivos sectoriales, nacionales, autonómicos y provinciales aplicables en el lugar de prestación de los servicios".

De tales preceptos se infiere que la determinación del precio de licitación requiere tener en cuenta salarios y demás condiciones laborales en los contratos de servicios en los que el coste fundamental sea el del personal que se adscriba a su ejecución, en cuanto indicativo del precio de mercado del contrato.

En cualquier caso, en la subrogación, respecto de la información necesaria para la exacta evaluación de los costes laborales, deberá atenderse a lo que a tal efecto señala el Art. 130.1 de la LCSP, que postula que "(...) en todo caso se deberán aportar los listados del personal objeto de subrogación, indicándose: el convenio colectivo de aplicación y los detalles de categoría, tipo de contrato, jornada, fecha de antigüedad, vencimiento del contrato, salario bruto anual de cada trabajador, así como todos los pactos en vigor aplicables a los trabajadores a los que afecte la subrogación. (...)”.

No se han acreditado las exigencias que para la fijación del presupuesto base de licitación determina el Art. 100.2 de la LCSP, sin que tampoco pueda considerarse que se ha procedido a la determinación del valor estimado del contrato en los concretos términos que preceptúa el Art. 101.2 de la LCSP.

En este sentido, el Art. 122.2 de la LCSP establece que "en los pliegos de cláusulas administrativas particulares se incluirán (...) la obligación del adjudicatario de cumplir las condiciones salariales de los trabajadores conforme al Convenio Colectivo sectorial de aplicación (...)”. Es decir, la LCSP lo establece como un límite, un elemento mínimo homogeneizador, un parámetro de referencia para evitar el dumping salarial en la licitación de los contratos públicos (mejorable en su caso por el convenio de empresa).

De conformidad con lo expuesto, concluye el Tribunal que el recurso debe estimarse, a los efectos de que con anterioridad a la aprobación de los nuevos pliegos, se configuren el presupuesto base de licitación y el valor estimado del contrato según lo establecido en la LCSP.

Para ello deberán consignarse en el presupuesto base de licitación los costes directos e indirectos y otros eventuales gastos, así como los costes salariales estimados a partir del convenio laboral sectorial, de forma desglosada y con desagregación de 
género y categoría profesional. Para el cálculo del valor estimado deberá observarse adecuadamente lo previsto en el Art. 101.2 de la LCSP' ${ }^{21}$.

\section{CRITERIOS DE ADJUDICACIÓN}

\section{Mayor número de centrales de respaldo en territorio nacional. Límite máximo}

En la resolución del TACRC que versa sobre esta cuestión ${ }^{22}$, la recurrente critica que este requisito de valoración ${ }^{23}$ al entender que 1) no valora aspectos vinculados al contrato licitado, 2) no guarda relación con el objeto del contrato, al exigir centros de respaldo fuera del ámbito territorial de contrato, y 3 ) vulnera la obligación legal de que las mejoras tengan un límite máximo.

\section{A. Mayor número de centrales}

El órgano de contratación alega que una mayor disponibilidad de centrales de respaldo a lo largo del territorio nacional, permite, ante circunstancias excepcionales, que las diversas centrales puedan hacerse cargo del servicio para las localidades de Alicante y Elche, asegurando así la prestación del servicio ante cualquier tipo de eventualidad.

El Tribunal comparte esta apreciación, y considera que el criterio de adjudicación sí está vinculado al objeto del contrato, en la medida en que puede mejorar la ejecución del servicio.

B. Límite máximo de unidades

En cambio, el Tribunal considera que ha de ser estimada la pretensión relativa a la necesidad de establecer un límite máximo del número de centrales de respaldo a ofrecer, toda vez que no se trata de una prestación que se vaya a realizar en todo caso, sino únicamente ante "circunstancias excepcionales", que podrían no llegar a producirse. Incluso de tener lugar alguna eventualidad, podría suceder que no se necesitaran todas las centrales de respaldo indicadas, sino solamente una o algunas. Por tanto, el criterio de adjudicación se entiende que vulnera el principio de proporcionalidad, de salvaguarda de la libre competencia, y selección de la oferta económicamente más ventajosa, ya que favorece injustificadamente a las empresas más grandes, en detrimento de las PYME, s.

Se estima el recurso, declarando la necesidad de establecer un límite máximo al número de centrales de respaldo a ofertar ${ }^{24}$.

En relación con la no concreción de la fórmula aplicable, se desestima el recurso porque con los datos ofrecidos por el pliego de cláusulas administrativas particulares (en adelante, PCAP) se pone de manifiesto que el criterio de adjudicación

\footnotetext{
${ }^{21}$ En su virtud, al amparo de lo establecido en los Arts. 57 de la LCSP y 61 de la Ley 1/2012, de 28 de febrero, el Tribunal Administrativo de Recursos Contractuales de Castilla y León resuelve estimar el recurso.

${ }^{22}$ Resolución nº141/2019 del TACRC, de 18 de febrero de 2019.

${ }^{23}$ Se otorgaban 3 puntos (Cláusula 6.2.a.2 del pliego).

${ }^{24}$ Resolución n ${ }^{\circ} 141 / 2019$ del TACRC, de 18 de febrero de 2019.
} 
establece para su valoración objetiva una proporcionalidad directa (una regla de tres directa). No obstante, dado que se anulan los pliegos, el órgano de contratación puede valorar la conveniencia de incluir la fórmula matemática concreta ${ }^{25}$.

\section{Mayor número de unidades móviles en la provincia}

En cuanto al mayor número de unidades móviles en la provincia ${ }^{26}$, el TACRC ${ }^{27}$ observa que efectivamente el criterio no exige que las unidades móviles adicionales se vinculen directamente a la prestación objeto del contrato, limitándose a puntuar el hecho de contar con un mayor número de unidades móviles (vehículos) en la provincia. En estos términos, por los mismos motivos mencionados (referidos al número máximo de unidades) y con los mismos fundamentos legales, estima el recurso para que se establezca un límite máximo al número de vehículos a ofertar, por encima del cual la Administración considere que no le reportará beneficio alguno el hecho de que el licitador cuente con una mayor flota de vehículos adicionales disponibles.

\section{Prestación de servicios complementarios}

Sobre este criterio de impugnación, lo primero que hay que indicar es que la recurrente formula el motivo de impugnación de forma vaga y poco precisa.

Así, en primer lugar, considera que este criterio de juicio de valor, el de las prestaciones complementarias, tiene un importante peso sobre la decisión de adjudicación. La recurrente yerra en tal afirmación: las prestaciones complementarias impugnadas por la recurrente en la Cláusula 6.2.b.2 tienen asignados 9 puntos sobre un total de 100 puntos, esto es (y de manera proporcional) un $9 \%$ del total de los puntos.

La recurrente afirma, también, que estas prestaciones complementarias deberían ser más definidas por el órgano de contratación. El TACRC no comparte la afirmación de la recurrente, por cuanto lo que se pretende a través de las prestaciones complementarias son servicios adicionales que pudiesen llegar a ofertar los eventuales licitadores con el objeto, principalmente, de mejorar o adicionar al servicio el knowhow de los prestadores de servicios, siendo por tanto la configuración de estos juicios de valor, $\operatorname{correctos}^{28}$.

\section{Plan de formación}

En la resolución del TACRC tomada como referencia ${ }^{29}$, el recurrente considera que la exigencia de los planes de formación ${ }^{30}$ que ya tengan aprobados los licitadores no es un criterio vinculado al contrato, sino que es una característica de la empresa en su conjunto, citando la Resolución nº60/2018 del TACRC.

\footnotetext{
${ }^{25}$ Resolución nº 115/2019 del TACRC, de 18 de febrero de 2019.

${ }^{26}$ (Cláusula 6.2.a.6 del pliego).

${ }^{27}$ Resolución n⿳0 $141 / 2019$ del TACRC, de 18 de febrero de 2019.

${ }^{28}$ Resolución n ${ }^{\circ} 115 / 2019$ del TACRC, de 18 de febrero de 2019.

${ }^{29}$ Resolución $n^{\circ} 141 / 2019$ del TACRC, de 18 de febrero de 2019.

30 Pliegos para la contratación de los "servicios de teleasistencia domiciliaria del Ayuntamiento de Alicante y el Ayuntamiento de Elche”.
} 
El Tribunal considera que el criterio sí está vinculado al objeto del contrato, ya que puede redundar en una mejor prestación del servicio, en la medida en que se interprete que los cursos establecidos en el Plan de formación, independientemente de que se impartan a trabajadores de la empresa de otros centros de trabajo, se dirijan necesariamente a los trabajadores que van a efectuar la prestación objeto del contrato.

\section{SUBROGACIÓN DE TRABAJADORES}

A continuación, se van a analizar distintas cuestiones relacionadas con la subrogación de trabajadores partiendo de la Resolución n546/2018 del TACRC ${ }^{31}$.

\section{Inclusión en pliegos de una cláusula en virtud de la cual se impone al adjudicatario la subrogación de los trabajadores adscritos al servicio}

En el presente caso, el órgano de contratación sostiene que la base de la imposición de esta obligación es la redacción de los Arts. 70 y 71 del VI Convenio Colectivo Marco Estatal de servicios de atención a las personas dependientes y de promoción a la autonomía personal, publicado en el BOE del 18 de mayo de $2012^{32}$.

En cuanto al citado Convenio Colectivo, lo primero que ha de indicarse es que las empresas o unidades de negocio que prestan servicios de teleasistencia en el territorio español están sujetas al mismo, el cual a la fecha de publicación de los pliegos todavía resultaba vigente y aplicable a las mismas. Establecida la aplicabilidad del convenio procede estudiar si efectivamente se recoge una obligación de subrogación del personal que fundamente la obligación ahora impugnada que tiene su reflejo en los pliegos. Y efectivamente los Arts. 70 y 71 del convenio recogen de forma expresa e inequívoca la obligación de subrogación de los trabajadores de la adjudicataria saliente, y con una mención específica en relación a las empresas dedicadas al servicio de teleasistencia, en los términos que se recogen en los mencionados artículos. De su lectura se desprende que existe una obligación de subrogación de los trabajadores que se corresponde con la prevista en el pliego, por lo que la impugnación resulta improcedente atendido el origen convencional de la obligación. Por ello debe desestimarse este motivo de impugnación.

\section{Exigir que dicha subrogación se produzca antes de la firma del contrato y como condición esencial al mismo}

El segundo de los motivos de impugnación afecta a la eficacia jurídica que los pliegos atribuyen a la acreditación de la realización de la subrogación, pues hacen depender la firma del contrato de la de la acreditación de la efectiva subrogación del personal.

Sostiene la parte actora que tal configuración resulta inviable por cuanto hasta la firma no se produce la adjudicación, no pudiendo verificarse la subrogación hasta este punto.

\footnotetext{
${ }^{31}$ Resolución n546/2018 del TACRC, de 1 de junio de 2018.

32 Ahora VII Convenio colectivo marco estatal de servicios de atención a las personas dependientes y desarrollo de la promoción de la autonomía personal (código de convenio 99010825011997), publicado en el "BOE" de 2 de septiembre de 2018, revisión y tablas que han sido suscritas, con fecha 28 de febrero de 2019 y publicadas en el BOE nº76 de 29 de marzo de 2019.
} 
Independientemente de que la recurrente no diferencia adecuadamente entre los términos "adjudicación" y "formalización" (término éste al que se refiere el pliego, al hablar de la "firma del contrato"), debe analizarse si la Administración puede o no condicionar la formalización al cumplimiento de la obligación de subrogación. Respecto del establecimiento de condiciones específicas a la ejecución de la obligación de subrogación, este Tribunal tiene asentada determinada doctrina aplicable al caso, por todas se puede citar la Resolución n n $^{\circ} 81 / 2017$ de 3 de octubre, cuyo fundamento octavo recoge lo siguiente:

La conclusión a la que se llega de conformidad con el Art. 120 del TRLCSP, es la de que este artículo no faculta al órgano de contratación para imponer la obligación de subrogación en el PCAP, así como tampoco le permite determinar el alcance de la obligación laboral de subrogación, sino que solamente le obliga a velar para que se consigne dicha información en los Pliegos, o en documentación complementaria, pero solo en el caso de que existiera una obligación laboral de subrogación. La conclusión anterior no obsta para considerar que los Pliegos pueden contener ciertas directrices que determinen como se puede cumplir con la eventual obligación de subrogación que corresponda al adjudicatario del contrato en cuestión. Así, podrían servir de fundamento para condicionar el modo en el que se desarrollará la relación laboral entre el adjudicatario, que adquiere la condición de empleador, y los trabajadores que se incorporan a su empresa por vía de subrogación. En este sentido, se dicta la Resolución $\mathrm{n}^{\circ} 468 / 2017$, de 7 de julio, en la que se exponía que: "si bien el empresario es soberano en el ejercicio de sus potestades de dirección y organización en el seno de su empresa, sin más límites que los que puedan imponer los derechos fundamentales de los trabajadores, las leyes de carácter laboral o los Convenios Colectivos (art. 1.1 y 20 del Real Decreto Legislativo 2/2015, de 23 de octubre, por el que se aprueba el Texto Refundido de la Ley del Estatuto de los Trabajadores), no podemos olvidar que los Pliegos establecen el clausulado que regulan la adjudicación del contrato administrativo, así como las normas que han de regir su posterior ejecución, erigiéndose en la ley de contrato (Resoluciones 334/2015, 704/2015 y 460/2017). El empresario/licitador que resulte adjudicatario deberá adecuar su organización empresarial a los términos de la oferta por él formulada y a la que se comprometió, y cumplir con ello lo exigido por el Pliego, so pena de incurrir, si así no lo hiciera, en las responsabilidades que se hayan establecido. Es por ello que, en virtud de lo expuesto, debe desestimarse la impugnación que realiza el recurrente de la Cláusula 4, apartado C, del PPT, al no invadir la potestad de organización del empresario contratista. Simplemente, y en lo relativo al tema de la subrogación del personal establece ciertas directrices a cumplir por la contratista para el caso de posibles modificaciones del organigrama y el equipo ofertado y aceptado. Estamos, en concreto, ante cinco directrices relativas a cualquier modificación del organigrama del personal de la adjudicataria al adscrito a la prestación del servicio contratado, directrices que van de la simple comunicación al Ayuntamiento a la autorización cuando se trata de reducción del número anual medio del personal descrito, suplencias de bajas y ausencias, etc., todo ello o a los solos efectos de controlar la subrogación y la elevación de costes como consecuencia del aumento del personal subrogable y el consiguiente incremento de costes, lo que no implica, de acuerdo con lo razonado, que se incurra en una injerencia de la potestad de organización del empresario, pues estamos ante la potestad de dirección del contrato y de vigilancia del cumplimiento de lo pactado que corresponde al órgano de contratación". 
En el presente caso, el Art. 70 del convenio colectivo de aplicación establece un conjunto de obligaciones de comunicación de la empresa cesante a la nueva empresa adjudicataria.

También regula lo que denomina "compensaciones económicas" entre las empresas, con motivo de las vacaciones de los trabajadores.

Se puede comprobar que la regulación que realiza el Art. 156 TRLCSP $^{33}$ sobre la formalización del contrato no ampara ni permite que ésta se condicione en modo alguno, y que la formalización tiene que entenderse como un acto a realizar una vez cumplimentadas las exigencias del mencionado precepto, sin que le esté dado al órgano de contratación incorporar condiciones suspensivas adicionales, sin perjuicio que el incumplimiento de éstas puedan tener en la dinámica o pervivencia del contrato, pero sin que puedan afectar a su formalización.

Además, con arreglo al Art. 27 del TRLCSP ${ }^{34}$ los contratos se perfeccionan con su formalización, esto es, con su firma, por lo que la obligación de la nueva adjudicataria de subrogación en los contratos laborales de la saliente, establecida en la normativa laboral de aplicación, no se produce hasta ese momento; hasta que se perfecciona el contrato. Por lo tanto, no puede exigirse acreditar la efectiva subrogación del personal antes de la firma del contrato.

El recurso debe ser estimado en este punto, por lo que procede la anulación de las Cláusulas 17.2 y 25 del Cuadro de Características particulares, y la retroacción del procedimiento al momento anterior a la aprobación del mencionado pliego.

A. Precio en atención a las obligaciones de subrogación

Se pretende que el órgano de contratación fije el precio en atención a las obligaciones de subrogación que impone el convenio colectivo aplicable, lo que no puede ser aceptado ${ }^{35}$.

A ello debe añadirse que no se ha acreditado, como se argumenta en el recurso interpuesto, que las obligaciones salariales del personal a subrogar superen el precio de licitación; pues para ello la recurrente ha tenido en cuenta al $100 \%$ de los trabajadores que se incluyeron en una primera lista en la información suministrada por la actual adjudicataria, pese a que después se aclaró (publicándose la mencionada aclaración en el perfil del contratante) que el número de trabajadores subrogables que pertenecen a la central de teleasistencia lo son en proporción al número de usuarios, de forma que en el momento de realizarse la aclaración el porcentaje de dedicación de la central era del $38,54 \%$, siendo solo subrogables al $100 \%$ los trabajadores relacionados con la unidad de servicio, que en el contrato objeto de este recurso ascienden a dos trabajadores según informa el órgano de contratación. Todo ello conforme se desprende del sentido literal del Art. 71 del Convenio de la Dependencia, que no impone una obligación total de subrogación, sino parcial por categorías de trabajadores distinguiendo entre la central de teleasistencia y la unidad o unidades de servicios.

\footnotetext{
${ }^{33}$ Ahora Art. 153 de la LCSP.

${ }^{34}$ Ahora Art. 36 de la LCSP.

${ }^{35}$ Resolución n ${ }^{\circ} 1123 / 2017$ del TACRC, de 24 de noviembre de 2017.
} 
En definitiva, el cálculo de los costes laborales derivados de la obligación de subrogación que hace la recurrente no es acertado, pues no tiene en consideración que parte de los trabajadores incluidos en el listado inicial no son subrogables.

B. Considerar el contrato económicamente inviable atendidos los gastos de personal a subrogar que constan en la documentación de la licitación

Este argumento ha de ser desestimado, pues no se sostiene en el más mínimo esfuerzo probatorio o justificativo de tal insuficiencia, ni desde luego se descredita el informe que obra en el expediente sobre la suficiencia económica del contrato. Así en el informe de 15 de febrero de 2018 se indica que "el presupuesto del contrato para la prestación del Servicio de Teleasistencia Municipal, durante los dos años de duración inicial del mismo y para un máximo de 2.900 dispositivos al mes, es de: $1.194 .336,00 €$ IVA incluido, correspondiendo 45.936,00€ al IVA estimado al 4\%. El precio del contrato, de conformidad con el artículo 302 del TRLCSP $^{36}$ se ha determinado por unidad de ejecución, partiendo del precio mensual de prestación del servicio por usuario titular de terminal, fijándose el tipo máximo de licitación en 16,50 e/mes por usuario titular de terminal".

De igual modo, tal y como se desprende del informe del órgano de contratación, el precio prevé un máximo del $72 \%$ del precio de licitación destinado a gastos de personal, de acuerdo con las obligaciones de subrogación de trabajadores previstas, de lo que se deduce que existe margen suficiente para que los licitadores puedan ajustar sus ofertas de conformidad con criterios de eficacia y eficiencia en la gestión.

En cualquier caso, la falta de prueba de la aseveración del recurrente es elemento suficiente para desestimar este motivo.

\section{EXCLUSIÓN DE OFERTA POR SUPERAR EL TIPO DE LICITACIÓN. SOLICITUD DE ACLARACIONES}

En la resolución del TACRC que sirve de base para explicar esta cuestión ${ }^{37}$, esgrime la empresa recurrente que la oferta económica incurrió en un error al consignar el precio ofrecido, pues la cantidad estaba referida al precio mensual del servicio, y no al precio diario, tal y como se requiere en los Pliegos.

Justifica su error la empresa al indicar que la práctica habitual en esta clase de contrato consiste en ofertar un precio mensual y no un precio diario. Se señalan en el recurso varias licitaciones, tanto a nivel autonómico como nacional, en el que se da la mencionada circunstancia. Se expone que resulta algo excepcional que se indique en esta clase de contratos el precio diario, y no el mensual.

Señala también el recurrente que en diversas cláusulas del contrato se hacen menciones que refuerzan el carácter mensual de la licitación, así la Cláusula 28.1 del PCAP, que se refieren al régimen de pagos del servicio, y al Anexo VII del PPT, relativo a los Cuadros Resumen Mensuales del Servicio, que fija el coste por mes del servicio.

\footnotetext{
${ }^{36}$ Ahora Art. 309 de la LCSP.

${ }^{37}$ Resolución n ${ }^{\circ} 122 / 2018$ del TACRC, de 9 de febrero de 2018.
} 
Debemos invocar en este punto la Resolución n ${ }^{\circ} 1109 / 2017$ del TACRC, de 24 de noviembre de $2017^{38}$. Por su parte, este Tribunal ha aplicado el criterio de la JCCA, entre otra muchas, en las Resoluciones 128/2011, 184/2011, 225/2013 y 92/2014, donde ha configurado una doctrina favorable a la subsanación de los defectos formales en la documentación acreditativa del cumplimiento de los requisitos de los licitadores, pero no de la existencia del requisito en el momento en que sea exigible. De conformidad con este criterio, viene admitiendo este Tribunal (por todas, la Resolución n ${ }^{\circ} 463 / 2014$ ) la posibilidad de subsanar defectos formales en la oferta técnica o económica. Pues bien, como ya ha puesto de relieve en Resoluciones anteriores (como referencia en la $\mathrm{n}^{\mathrm{o}} 614 / 2013$, de 13 de diciembre), la subsanación de errores u omisiones en la documentación relativa a la oferta, únicamente es posible cuando no implique la posibilidad de que se modifique la proposición después de haber sido presentada. En la mencionada Resolución, se hacía referencia a la sentencia de 29 de marzo de 2012 del Tribunal de Justicia de la Unión Europea ${ }^{39}$.

Siguiendo lo declarado en la Resolución 876/2014, cabe señalar que:

"Este Tribunal se ha ocupado en numerosas resoluciones sobre el particular; ante todo, se ha de recordar que, como regla general, nuestro Ordenamiento (artículo 81 RGLCAP) sólo concibe la subsanación de los defectos que se aprecien en la documentación administrativa, no en la oferta técnica o en la económica (cfr. Resolución 151/2013), y ello, además, en el sentido de que la subsanación se refiere a la justificación de un requisito que ya se ha cumplido y no a una nueva oportunidad para hacerlo (Resoluciones 128/2011, 184/2011, 277/2012 y 74/2013, entre otras). Respecto de la oferta técnica, hemos declarado, en cambio, que no existe "obligación alguna por parte del órgano de contratación de solicitar subsanación de la misma y debiendo soportar el licitador las consecuencias del incumplimiento de su deber de diligencia en la redacción de la oferta" (Resolución 016/2013), conclusión que se infiere de la doctrina sentada por el Tribunal de Justicia de la Unión Europea, Sala Cuarta, de 29 de marzo de 2012 (asunto C-599/2010). Lo que sí es posible es solicitar "aclaraciones que en ningún caso comporten alteración de la oferta, pero no la adición de otros elementos porque ello podría representar dar la opción al licitador afectado de modificar su

\footnotetext{
${ }^{38}$ Cuyo fundamento de derecho cuarto exponía lo siguiente:

"Como ha resuelto este Tribunal en, entre otras, resolución 661/2017 de 21 de julio, "Con carácter general la JCCA viene entendiendo (informe 18/10, de 24 de noviembre, con cita de los informes 9/06, de 24 de marzo de 2006, 36/04, de 7 de junio de 2004, 27/04, de 7 de junio de 2004, 6/00, de 11 de abril de 2000, 48/02, de 28 de febrero de 2003, o 47/09, de 1 de febrero de 2010) que "se reconoce como subsanable, ya sea por errores u omisiones, la aportación de documentos exigidos para concurrir siempre que el contenido del mismo, como elemento acreditativo, exista en el momento en que se presenta y en el momento en que concluye el plazo de presentación de proposiciones, que evidentemente es anterior al momento de subsanación. Es decir, puede subsanarse lo que existe, pero no se ha aportado; no se puede subsanar lo que en el momento citado no existe de manera indudable. Esta interpretación está en línea con la reiterada jurisprudencia del Tribunal Supremo en cuanto a que un excesivo rigor al aplicar las normas de procedimiento puede conducir a una infracción del principio básico de contratación administrativa de la libre concurrencia a través del rechazo de los licitadores por defectos formales. Así, la interpretación que da esta Junta Consultiva ofrece un compromiso entre los principios de no discriminación e igualdad de trato, antes citados, y el principio de libre concurrencia".

39 Que, entre otras cuestiones, admitía que "excepcionalmente, los datos relativos a la oferta puedan corregirse o completarse de manera puntual, principalmente porque sea evidente que requieren una mera aclaración o para subsanar errores materiales manifiestos, a condición de que esa modificación no equivalga a proponer, en realidad, una nueva oferta".
} 
proposición lo que comportaría notable contradicción con el principio de igualdad proclamado como básico de toda licitación en los artículos 1 y 139 del Texto Refundido de la Ley de Contratos del Sector Público" (Resolución 94/2013)”.

De acuerdo con estas consideraciones, entiende este Tribunal que, siendo admisible solicitar aclaraciones respecto de las ofertas técnicas o económicas, "debe considerarse que ese ejercicio de solicitud de aclaraciones tiene como límite que la aclaración no puede suponer una modificación de los términos de la oferta, bien por variar su sentido inicial, bien por incorporar otros inicialmente no previstos (Resoluciones 64/2012, 35/2014 y 876/2014, entre otras)". Por su parte, este Tribunal ha aplicado el criterio de la JCCA, entre otra muchas, en las Resoluciones 128/2011, 184/2011, 225/2013, y 92/2014, donde ha configurado una doctrina favorable a la subsanación de los defectos formales en la documentación acreditativa del cumplimiento de los requisitos de los licitadores, pero no de la existencia del requisito en el momento en que sea exigible. De acuerdo con este criterio, viene admitiendo este Tribunal (por todas, Resolución 463/2014) la posibilidad de subsanar defectos formales en la oferta técnica o económica. Pues bien, como ya se ha indicado en Resoluciones anteriores (como referencia en la $\mathrm{n}^{\circ} 614 / 2013$, de 13 de diciembre), la subsanación de errores u omisiones en la documentación relativa a la oferta, sólo es posible cuando no implique la posibilidad de que se modifique la proposición después de haber sido presentada. En la citada Resolución, se hacía referencia a la sentencia de 29 de marzo de 2012 del Tribunal de Justicia de la Unión Europea que, entre otras cuestiones, admitía que "excepcionalmente, los datos relativos a la oferta puedan corregirse o completarse de manera puntual, principalmente porque sea evidente que requieren una mera aclaración o para subsanar errores materiales manifiestos, a condición de que esa modificación no equivalga a proponer, en realidad, una nueva oferta".

Siguiendo lo declarado en la Resolución nº876/2014, cabe señalar que:

"Este Tribunal se ha ocupado en numerosas resoluciones sobre el particular; ante todo, se ha de recordar que, como regla general, nuestro Ordenamiento (artículo 81 RGLCAP) sólo concibe la subsanación de los defectos que se aprecien en la documentación administrativa, no en la oferta técnica o en la económica (cfr. Resolución 151/2013), y ello, además, en el sentido de que la subsanación se refiere a la justificación de un requisito que ya se ha cumplido y no a una nueva oportunidad para hacerlo (Resoluciones 128/2011, 184/2011, 277/2012 y 74/2013, entre otras). Respecto de la oferta técnica, hemos declarado, en cambio, que no existe "obligación alguna por parte del órgano de contratación de solicitar subsanación de la misma y debiendo soportar el licitador las consecuencias del incumplimiento de su deber de diligencia en la redacción de la oferta" (Resolución 016/2013), conclusión que se infiere de la doctrina sentada por el Tribunal de Justicia de la Unión Europea, Sala Cuarta, de 29 de marzo de 2012 (asunto C-599/2010). Lo que sí es posible es solicitar "aclaraciones que en ningún caso comporten alteración de la oferta, pero no la adición de otros elementos porque ello podría representar dar la opción al licitador afectado de modificar su proposición lo que comportaría notable contradicción con el principio de igualdad proclamado como básico de toda licitación en los artículos 1 y 139 del Texto Refundido de la Ley de Contratos del Sector Público" (Resolución 94/2013)”.

De acuerdo con estas consideraciones, entiende este Tribunal que, siendo admisible solicitar aclaraciones respecto de las ofertas técnicas o económicas, "debe 
considerarse que ese ejercicio de solicitud de aclaraciones tiene como límite que la aclaración no puede suponer una modificación de los términos de la oferta, bien por variar su sentido inicial, bien por incorporar otros inicialmente no previstos" (Resoluciones 64/2012, 35/2014, y 876/2014, entre otras). Lo decisivo es que la aclaración no propicie el otorgamiento de un trato de favor a un interesado en detrimento de los demás licitadores, en el sentido de que diera lugar a que aquél, después de conocer el contenido de las otras ofertas, pudiera alterar la proposición inicialmente formulada. Así se entiende el sentido del último inciso del artículo 84 RGLCAP, cuando admite que se puedan variar algunas palabras del modelo "cuando no alteren su sentido".

Sin embargo, el de igualdad no es el único principio que ha de tenerse en cuenta a la hora de abordar la controversia suscitada, debiendo, asimismo, considerarse el principio de concurrencia, que aboga por favorecer la admisión de licitadores al procedimiento, proscribiendo que puedan ser excluidas proposiciones por la presencia de errores fácilmente subsanables, dado que, como afirma la Sentencia del Tribunal Supremo de 21 de septiembre de 2004 "una interpretación literalista de las condiciones exigidas para tomar parte en los procedimientos administrativos de contratación, que conduzca a la no admisión de proposiciones por simples defectos formales, fácilmente subsanables, es contraria al principio de concurrencia, que se establece en el artículo 13 de la Ley de Contratos del Estado, de 8 de abril de 1.965, así como que la preclusión de aportaciones documentales tiene por objeto evitar sorpresas para los demás concursantes, o estratagemas poco limpias, pero no excluir a los participantes por defectos en la documentación de carácter formal, no esencial, que, como hemos dicho, son subsanables sin dificultad, doctrina que se encuentra recogida en anteriores sentencias de la Sala, como las de 22 de junio de 1.972, 27 de noviembre de 1.984 y 19 de enero de 1.995".

En virtud de ello, se infiere el alcance del Art. 84 del RGLCAP, cuya impronta debe circunscribirse a aquellos supuestos en los que el error del que adolece la proposición del licitador no es salvable mediante la lectura de la propia oferta o de la documentación que, requerida por el pliego, la acompañe. Ésta ha sido la línea seguida por este Tribunal, que, si con carácter general ha negado la posibilidad de subsanar o aclarar los términos de las ofertas (Resoluciones 164/2011, 246/2011, 104/2012, 268/2012, 16/2013, 117/2013, 151/2013), ha rechazado la exclusión de aquéllas donde el error podía salvarse de forma inequívoca con la documentación presentada (Resoluciones 84/2012, 96/2012, 237/2012, 278/2012), pero no cuando los términos de la oferta son susceptibles de varias lecturas (Resolución 283/2012).

Partiendo, pues, de la excepcionalidad de la solicitud de aclaraciones sobre las ofertas técnica y económica de los licitadores, en el supuesto que examinamos no existe, según se desprende del expediente, ninguna duda u oscuridad en la proposición de la entidad recurrente sobre la que se plantee la procedencia de solicitar aclaraciones por parte del órgano de contratación. Por ello el recurso debe ser desestimado, confirmándose el acuerdo de exclusión por ser ajustado a Derecho.

\section{INSUFICIENCIA DE INFORMACIÓN A LOS LICITADORES}


Cabe analizar si la insuficiencia de información a los licitadores ${ }^{40}$ distintos del prestador actual del servicio puede conllevar la vulneración de los principios de igualdad y no discriminación.

Es necesario distinguir a efectos de la aplicación del principio de transparencia, pero también, de los de igualdad, no discriminación y libre concurrencia, entre el contenido de los pliegos y la contestación a las preguntas o aclaraciones, o a la solicitud de información adicional a la facilitada con los pliegos.

El juego de los citados principios ha de producirse no solo en los pliegos sino también en la contestación a las solicitudes de aclaración e información sobre aquellos o la entera licitación.

Puede suceder que conteniendo los pliegos la información mínima necesaria para la formulación de la oferta, exista información adicional para los prestadores actuales del servicio que les coloquen en una situación de ventaja, y consiguientemente de desigualdad discriminatoria, respecto de los demás licitadores.

Así no se cumple con la garantía de la libre concurrencia, que no es sino la concreción del principio de igualdad de trato en el procedimiento de licitación, con solo la publicación de la información suficiente para licitar, sino que el órgano de contratación debe promover la efectividad de tal principio, permitiendo a todos los licitadores el acceso a la misma información en pie de igualdad, impidiendo con ello la creación de ventajas discriminatorias entre ellos, que atenten contra la libre y leal competencia.

A esto se refiere el Art. 18.1 de la Directiva 2014/24 ${ }^{41}$.

Este precepto contempla los principios generales por los que debe regirse la contratación pública, que se extienden a todas las fases de la contratación, licitación, ejecución y extinción. Es una norma de efecto directo, de un efecto orientador de la actividad de la compra pública, que no necesita por si de transposición, además de que puede considerarse ya incorporado en nuestro ordenamiento en el Art. 1 del TRLCSP ${ }^{42}$.

El principio de transparencia, que es esencial al conjunto del actuar de los poderes públicos - sobre todo en nuestro ordenamiento desde la entrada en vigor de la Ley 19/2013, de 9 de diciembre, de transparencia, acceso a la información pública y buen gobierno- , tiene una particular dimensión en la contratación pública, pues es uno de los modos en que se hacen efectivos los principios de libre concurrencia, igualdad de trato y no discriminación, y su realización efectiva constituye para la Administración contratante, no una facultad de la que puede decidir arbitrariamente hacer uso, sino un

\footnotetext{
${ }^{40}$ Resolución $n^{\circ} 428 / 2017$ del TACRC, de 12 de mayo de 2017.

41 "Los poderes adjudicadores tratarán a los operadores económicos en pie de igualdad y sin discriminaciones, y actuarán de manera transparente y proporcionada.

La contratación no será concebida con la intención de excluirla del ámbito de aplicación de la presente Directiva ni de restringir artificialmente la competencia. Se considerará que la competencia está artificialmente restringida cuando la contratación se haya concebido con la intención de favorecer o perjudicar indebidamente a determinados operadores económicos".

${ }^{42}$ Ahora Art. 1 de la LCSP.
} 
deber, parejo al derecho de los licitadores a obtener una información que garantice la igualdad de trato ${ }^{43}$.

En este caso, la lesión a tales principios no surge tanto de la insuficiencia de los pliegos como de la actitud reticente, cuando no oscurantista, del órgano de contratación a facilitar la información requerida a las consultas y solicitudes formuladas.

En efecto, el órgano de contratación ha negado la información requerida por el licitador relativa al número de llaves custodiadas, la distribución territorial de las personas que van a recibir el servicio, existencia de detectores de seguridad o de cualquier otro tipo instalados en los domicilios de los usuarios, número de usuarios actualmente en el servicio por cada uno de los lotes, y número de usuarias que son titulares del servicio y cuantos son Beneficiarios con UCR, con idéntica respuesta "no es una información determinante para la presentación de ofertas", todo ello a pesar de que son datos de los que dispone el prestador actual del servicio, como por lo demás advierte la recurrente en alguna de sus preguntas, y no ha negado el órgano de contratación en su informe.

Ha vulnerado el órgano de contratación el principio de trasparencia, al no facilitar al licitador la información que solicitó, a pesar de disponer de ella el actual prestador del servicio, infringiendo el principio de igualdad de trato y afectando a la libre concurrencia.

Por eso es obligado que, como documentación complementaria a los pliegos, se ponga a disposición de todos los posibles licitadores la información adicional a la obrante en los pliegos, de la que dispone el actual prestador de servicio, y en particular la denegada al recurrente, para que puedan elaborar sus ofertas.

En cuanto a la vulneración de los principios mencionados por la falta de publicidad de las respuestas a las solicitudes de aclaraciones, no puede atenderse.

El propio recurrente en su escrito de recurso pone de manifiesto que el Art. 131.2 del TRLCSP rige exclusivamente para el contrato de concesión de obra pública, sin que se admita una aplicación analógica para con el resto de modalidades de $\operatorname{contratos}^{44}$.

\footnotetext{
43 "En relación a su aplicación, hemos señalado (por todas Resolución n917/2015, de 9 de octubre) que todos los posibles licitadores han de contar con información suficiente al momento de formular su oferta sobre los requisitos técnicos exigibles para la ejecución del contrato, pues de otro modo no podría formular una oferta seria. Asimismo que si la información suministrada por los pliegos o la documentación complementaria a aquellos es menor de la que tiene la empresa que actualmente presta el servicio y que puede presentarse a la licitación, se produce una lesión al principio de igualdad y no discriminación y, por tanto, una alteración de la libre concurrencia.

Tal omisión debe remediarse incorporando dicha información, en los mismos términos en que es conocida por el prestador actual del servicio, ya en los pliegos ya en documentación complementaria a ellos, y puesta a disposición de todos los licitadores, así como resolviendo cuantas dudas técnicas pudieran presentárseles de forma transparente y respetando la igualdad de condiciones".

${ }^{44}$ Sin embargo, ahora el Art. 138.3 de la LCSP dispone que "en los casos en que lo solicitado sean aclaraciones a lo establecido en los pliegos o resto de documentación y así lo establezca el pliego de cláusulas administrativas particulares, las respuestas tendrán carácter vinculante $\mathrm{y}$, en este caso, deberán hacerse públicas en el correspondiente perfil de contratante en términos que garanticen la igualdad y concurrencia en el procedimiento de licitación".
} 
No existe una obligación legal taxativa de hacer pública todas las contestaciones a las consultas planteadas en los demás tipos contractuales.

Si está en lo cierto el recurrente en cuanto a que la efectividad de los principios de transparencia, igualdad de trato y libre concurrencia puede exigir la puesta de manifiesto a todos los posibles licitadores de aquella contestación, pero tal exigencia no es independiente del contenido de la consulta y de la respuesta sino, antes bien, de la importancia que, para la realización del principio de igualdad de trato, tiene cada consulta y contestación producidas.

Así, cuando la contestación se limita a poner de manifiesto lo que aparece con claridad en los pliegos, y puede ser conocido por los licitadores, de forma que no añade información nueva a aquellos o no despeja dudas sobre los mismos, no es necesario hacer pública su contestación.

Lo mismo sucede cuando, como es el presente caso, se niega sin más la información solicitada.

Si bien la publicación en el perfil del contratante de todas las consultas y contestaciones formuladas es una buena práctica administrativa, dicha publicidad únicamente es exigible cuando de no producirse, se beneficie a un licitador en perjuicio de otros o viceversa, en fin, cuando el principio de igualdad de trato quede comprometido por la no publicación ${ }^{45}$.

En este caso, sobre todo dada la inanidad de las respuestas, el principio de igualdad de trato no se ha vulnerado por la no publicación de las consultas sino por su no contestación.

Aunque esta Resolución es anterior a la LCSP supuso un importante reconocimiento a la aplicación de los principios de publicidad, transparencia e igualdad, de modo que debe facilitarse información adicional a la contenida en los pliegos cuando los licitadores se encuentren en situación de desventaja respecto al anterior prestador del servicio y por lo tanto en desigualdad discriminatoria, situación que ya se regula claramente en el Art. 138.3 de la LCSP.

\section{FÓRMULA DE PROPORCIONALIDAD}

En la resolución tomada como referencia para aludir a este punto ${ }^{46}$, la recurrente alega que el órgano de contratación introduce una fórmula de proporcionalidad que no estaba prevista en los pliegos, no habiéndosele otorgado la puntuación debida, de conformidad con el criterio a aplicar ${ }^{47}$.

\footnotetext{
${ }^{45}$ Vid. Art. 138.3 de la LCSP.

${ }^{46}$ Resolución 58/2019 del Tribunal Administrativo de Recursos Contractuales de Castilla y León, de 16 de mayo.

47 5.-Servicio de localización permanente, dentro y fuera del domicilio, para enfermos con alteraciones cognitivas, alzheimer u otras dolencias: ... hasta 12 puntos.

1. Hasta 20 terminales anuales............ 12 puntos.

m. Hasta 10 terminales anuales............ 6 puntos.

n. Hasta 5 terminales anuales............ 1 puntos".
} 
En el caso examinado no cabe sino afirmar que los pliegos adolecen de la precisión y claridad exigible, estando redactados de una forma más que mejorable, y que los criterios de adjudicación no han sido objeto de justificación adecuada en el expediente, tal y como dispone el Art. 116.4 de la LCSP.

El recurrente considera que no se establece ninguna fórmula de proporcionalidad, sino el otorgamiento automático de los puntos conforme a los tramos específicos que se recogen en cada criterio, con una puntuación cerrada para cada tramo.

El recurrente afirma que, en el criterio relativo al servicio de localización permanente, ha obtenido una puntuación de 7,2 puntos al ofertar 12 terminales anuales, entendiendo que debió haber obtenido 12 puntos, (ha obtenido una puntuación total, por todos los criterios, de 95,20 puntos, frente a los 99,62 del adjudicatario).

Muestra su disconformidad con la valoración otorgada en el criterio relativo al servicio de localización permanente (valorable hasta con 12 puntos), entendiendo que de la literalidad de los pliegos, el reparto deberá realizarse así: si se oferta entre 1 y 5 terminales anuales, se otorgará 1 punto; si se oferta entre 6 y 10 terminales anuales, se otorgarán 6 puntos; si se oferta entre 11 y 20 terminales anuales, se otorgarán 12 puntos, y 0 puntos si no se ofertan terminales.

Aceptar la interpretación del recurrente supondría en el caso examinado que careciese de lógica el ofertar un número de terminales por encima del mínimo de cada intervalo para obtener la puntuación prevista para el mismo (sería, por ejemplo, absurdo ofertar 20 terminales anuales, si ofertando 11 se logra la misma puntuación, esto es, resulta absurdo ofertar 20 terminales anuales, si ofertando 11 se logra la misma puntuación).

Nadie ofertaría gratuitamente más terminales, que conllevan un mayor coste, para obtener los mismos puntos.

La interpretación que propugna el recurrente determina entender que en el intervalo inferior de hasta 5 terminales, por una diferencia de 5 veces más de productos ofertados (de 1 a 5) se otorgarían los mismos puntos, o que, respecto al límite superior, ofertando casi el doble de terminales (de 11a 20) se obtenga la misma puntuación, 12 puntos, y ello atendiendo a que en el criterio la puntuación tiene una importancia relativa muy decisiva en la adjudicación del contrato, dados los criterios a aplicar.

Se podría entender, dada la "peculiar" redacción del criterio examinado, que se está refiriendo con la preposición hasta (de conformidad con la RAE, segunda acepción, su significado usual en la materia que nos ocupa, debería hacer referencia al límite máximo de una cantidad variable) precisamente al límite indicado, (como si se tratase de la preposición por), esto es, que con hasta 20 terminales anuales, y precisamente únicamente con estos 20 terminales anuales, se otorgarán 12 puntos. En puridad, no se establece de modo expreso una banda de puntuación, como pudiera resultar, por ejemplo, de 11 a 20 terminales (o 11-20), hasta 20 puntos.

Es necesario indicar que los criterios examinados no deberían haber dado lugar a interpretación, debiendo bastar una mera aplicación de la fórmula previamente 
determinada en los pliegos, de forma clara, y que, no se establece, de modo expreso, una regla proporcional para la asignación de la puntuación de cada tramo, sin perjuicio de que una interpretación lógica pudiera suponer que dentro de cada tramo se deban aplicar proporcionalmente los puntos previstos. Entiende este tribunal que la Mesa de contratación ha concretado los elementos de valoración, con base en el criterio de adjudicación, tratando de objetivar las puntuaciones asignadas a cada oferta, en base a una regla proporcional de distribución de la puntuación.

Ante la manifestación de un disenso sobre el significado de las cláusulas contractuales, es preciso indagar el sentido que ha de atribuírseles y contemplar, desde una perspectiva global, sistemática o integradora, el régimen jurídico del contrato, en el que, como punto de partida, no pueden presumirse las contradicciones o antinomias.

A falta de disposiciones expresas en la normativa administrativa, constituyen un elemento primordial los criterios interpretativos previstos en los Arts. 1.281 a 1.289 del Código Civil, aplicables también respecto de los contratos administrativos, tal y como resulta del orden de fuentes establecido en el Art. 25.2 de la LCSP.

Por otro lado, no puede obviarse el efecto útil que se deriva del Art. 1.284 del Código Civil en cuanto dispone que si alguna cláusula de los contratos admitiese diversos sentidos, deberá entenderse en el más adecuado para que produzca efecto.

El Art. 1281 del Código Civil, precisa que si los términos de un contrato "son claros" y "no dejan duda sobre la intención de los contratantes", se estará al sentido literal de sus cláusulas, por lo que no resultaría, en tal caso posible, el valorar el resto de las restantes reglas interpretativas contenidas en los Arts. 1.282 a 1.289 del Código Civil. No obstante, de conformidad con su párrafo segundo, "si las palabras parecieren contrarias a la intención evidente de los contratantes, prevalecerá ésta sobre aquéllas".

Resulta necesario también tener en cuenta, sin perjuicio de la preponderancia que debe otorgarse a la interpretación literal de las cláusulas de los contratos (Art. 1.281 del CC), la intención evidente de los contratantes a la hora de interpretar los contratos, de acuerdo con lo señalado en el Art. 1.288 del Código Civil, que dispone que "para juzgar de la intención de los contratantes, deberá atenderse principalmente a los actos de éstos, coetáneos y posteriores al contrato".

En el supuesto examinado, respecto del criterio controvertido, todos los licitadores, salvo el recurrente (cuatro de cinco), han ofertado en el criterio de adjudicación indicado (relativo a los terminales anuales del servicio de localización permanente), el máximo previsto, 20 terminales anuales, por lo que todos han entendido que para obtener la máxima puntuación debería ofertarse el máximo del ítem correspondiente. También el propio recurrente en el resto de criterios de adjudicación distintos del precio (dispositivos periféricos y servicio de custodia de llaves), con una configuración idéntica al criterio examinado, ha ofertado el máximo correspondiente, tal y como puede observarse en el antecedente de hecho número dos, lo que dificulta considerar que la interpretación que propugna pudiera resultar compatible con lo que se deriva de sus propios actos.

Tampoco parece razonable que si el licitador considera que se establece un tramo de 11 a 20 terminales anuales en tal criterio para obtener 12 puntos (con 
independencia de los terminales ofertados siempre que estén dentro de dicho intervalo), oferte 12 terminales y no 11 .

En virtud de lo expuesto, procede desestimar el recurso interpuesto.

No consta que el recurrente hubiera solicitado aclaraciones o información al órgano de contratación, tal y como prevé el Art. 138 de la LCSP, o que, pese a la falta de concreción de los pliegos, interpusiera el correspondiente recurso frente a éstos, ni lo haga en el presente procedimiento.

Sobre esta última cuestión, la Sentencia del Tribunal de Justicia de la Unión Europea de 12 de marzo de 2015 (asunto eVigilo Ltd) concluye que "el artículo 1, apartado 1, párrafo tercero, de la Directiva 89/665 y los artículos 2, 44, apartado 1, y 53, apartado 1, letra a), de la Directiva 2004/18 deben interpretarse en el sentido de que exigen que un derecho de recurso relativo a la legalidad de la licitación sea accesible, tras el vencimiento del plazo previsto por el Derecho nacional, a un licitador razonablemente informado y normalmente diligente que no pudo comprender las condiciones de la licitación hasta el momento en que el poder adjudicador, tras haber evaluado las ofertas, informó exhaustivamente sobre los motivos de su decisión. Tal recurso podrá interponerse hasta que finalice el plazo de recurso contra la decisión de adjudicación del contrato".

Sobre esta base, los órganos encargados de la resolución de los recursos contractuales mantienen que no es admisible, por ir en contra del efecto útil de la Directiva de recursos, una interpretación del Art. 145.1 del TRLCSP que permita la existencia de causas de nulidad de pleno derecho, o infracciones de los principios básicos de la contratación pública, por presumir el consentimiento o aquiescencia del licitador por su mera participación en la licitación. Sin embargo, y como se señaló en la Resolución de este Tribunal 63/2017, de 7 de septiembre, "debe recordarse que el recurso especial en materia de contratación no está dirigido a conseguir una revisión general y abstracta de una decisión de un órgano de contratación, por el mero hecho de ser perjudicial para un licitador.

Este Tribunal resuelve, bajo el principio de congruencia, sobre las pretensiones concretas de las partes y no puede realizar de oficio una revisión general de cada extremo de los pliegos o de las actuaciones realizadas en el procedimiento por el órgano de contratación o por terceros (...) el recurrente no alega, ni trata de justificar, la existencia de un vicio de nulidad en el pliego, de entre los previstos en el artículo 32 del TRLCSP, y resulta manifiesto y no justificado que, habiendo tenido oportunidad para ello, no hubiera impugnado el criterio de adjudicación previsto en la cláusula 15 del PCAP mediante el correspondiente recurso contra el pliego interpuesto en plazo. El licitador presentó la oferta en los términos previstos en el PCAP y de conformidad con el modelo de oferta correspondiente, sin que conste que solicitara aclaraciones al poder adjudicador.

Mantiene la citada Sentencia del TJUE de 12 de marzo de 2015 (asunto C538/13), apartado 57 que "Si del citado examen resulta que las condiciones de la licitación eran efectivamente incomprensibles para el licitador y que se vio en la imposibilidad de interponer un recurso en el plazo previsto por el Derecho nacional, el licitador estará legitimado para interponer un recurso hasta que finalice el plazo previsto 
para recurrir contra la decisión de adjudicación del contrato"; esta situación, sin embargo, no concurre en el presente caso y se desestima por el Tribunal el recurso".

\section{EXCLUSIÓN DE OFERTA DE TELEASISTENCIA POR ANORMALMENTE BAJA}

Los Arts. 69 de la Directiva 2014/24 y 149 LCSP regulan las ofertas anormalmente bajas.

En la Resolución $n^{0} 1127 / 2018$ del TACRC, de 7 de diciembre de 2018 se analiza este supuesto, indicando que "por ello, cuando se entienda que haya elementos en la oferta que la hacen incongruente, desproporcionada o anormalmente baja, se puede proceder a la exclusión del procedimiento de licitación, cuando se estime que no puede ser cumplida".

Como se señaló en la Resolución 832/2014 del TACRC, de 7 de noviembre ${ }^{48}$, si bien en aquellos casos en los que el informe técnico no comparta la justificación dada por el licitador para justificar la anormalidad de su oferta, debe motivarse el informe (pues éste tendrá que salir al paso de lo alegado por el interesado rebatiendo su argumentación), esto no implica, ni quiere decir, que aquellos otros supuestos en los que se considere que el licitador ha dado razones suficientes para considerar que la oferta es viable a pesar de su apariencia de anormalidad o desproporción, se deba aducir necesariamente una motivación diferente de la ya expuesta en su escrito por el licitador. Siendo ésta suficiente, nada exige que el asesor técnico verifique no sólo la realidad de lo alegado sino también, si entiende justificada que la proposición no incurre en anormalidad que la haga inviable, recoja en el informe sus propias razones motivando el porqué de la razón que asiste al interesado ${ }^{49}$.

\section{CONFIDENCIALIDAD DE LA JUSTIFICACIÓN DE LAS BAJAS}

En la resolución de referencia sobre este tema ${ }^{50}$, la recurrente basa su recurso en la afirmación de que la calificación como confidencial de la justificación ofrecida por el licitador CR no resulta debidamente motivada, por descansar solamente en consideraciones estrictamente genéricas, extendiéndose a todos los particulares de contenido económico de dicha justificación y yendo más allá de los extremos concretamente designados como tales por la propia interesada. Al tiempo, afirma que la

\footnotetext{
48 Vid. Acuerdo del Tribunal Administrativo de Contratación Pública de la Comunidad de Madrid, Resolución 203/2018, de 11 de julio de 2018.

${ }^{49}$ En la Resolución 786/2014, de 24 de octubre, citando la Resolución 677/2014, de 17 de septiembre, se indicaba que "la revisión de la apreciación del órgano de contratación acerca de la justificación de las ofertas incursas en presunción de temeridad, incide directamente en la discrecionalidad técnica de la Administración, y que a tal respecto es criterio de este Tribunal (Resoluciones 105/2011 y las 104 y 138/2013) que la apreciación hecha por la entidad contratante del contenido de tales justificaciones en relación con el de las propias ofertas debe considerarse que responde a una valoración de elementos técnicos que en buena medida pueden ser apreciados en función de parámetros o de criterios cuyo control jurídico es limitado. Aun así hay aspectos que, aun siendo difíciles de controlar jurídicamente por venir determinados por la aplicación de conceptos jurídicos indeterminados, pueden y deben ser revisados por el Tribunal. Tal es el caso de que en una oferta determinada puedan aparecer síntomas evidentes de desproporción que impidan, sin necesidad de entrar en la apreciación de criterios puramente técnicos, la ejecución del contrato en tales condiciones".

${ }^{50}$ Resolución n ${ }^{\circ} 975 / 2018$ del TACRC, de 26 de octubre de 2018.
} 
oferta de la propuesta como adjudicataria es inviable, pues su importe no alcanza a cubrir los costes laborales del personal ofertado, que cifra en 1.629.037,81€.

Por su parte, tanto el órgano de contratación, en el informe remitido con ocasión de la interposición de este recurso, como la propia CR interesan la desestimación del recurso, por entender que la declaración de confidencialidad está motivada y se contrae a extremos que merecen esa calificación, negando la supuesta inviabilidad a que alude la recurrente.

En cuantiosas ocasiones (valga por todas la Resolución n¹48/2017) el TACRC ha declarado que la justificación ofrecida por los licitadores incursos en presunción de anormalidad o desproporción puede revestir carácter confidencial, "pues en dicha justificación pueden contenerse datos explícitos sobre procedimientos de gestión, económicos o estratégicos que sean efectivamente los que hacen viable la oferta".

Este mismo Tribunal ha declarado (valga por todas la Resolución n²91/2018, de 23 de marzo, que hace recensión de la doctrina sobre dicho particular) que ni el principio de confidencialidad es absoluto, ni tampoco lo es el de publicidad, por lo que "en el conflicto entre el derecho de defensa del licitador descartado y el derecho a la protección de los intereses comerciales del licitador adjudicatario, se ha de buscar el necesario equilibrio de forma que ninguno de ellos se vea perjudicado más allá de lo estrictamente necesario".

Sobre esta base se ha venido afirmando (en términos que, si bien referidos al contenido de las ofertas son trasladables a su justificación) que "esta obligación de confidencialidad no puede afectar a la totalidad de la oferta realizada por el adjudicatario, habida cuenta de que el propio artículo 140.1 del TRLCSP ${ }^{51}$ garantiza que este deber de confidencialidad no debe perjudicar el cumplimiento de las obligaciones en materia de publicidad e información que debe darse a candidatos y licitadores, obligaciones entre las que se encuentran incluidas las enumeradas en el artículo 151.4 del TRLCSP, habiendo entendido el Tribunal (Resolución 45/2013, de 30 de enero) que una extensión de la confidencialidad a toda la proposición del adjudicatario podría estar incursa en fraude de ley en los términos previstos en el artículo 6.4 del Código Civill". En este sentido, el Tribunal ha afirmado que "puesto que la adjudicataria del contrato de forma indiscriminada ha calificado como confidencial toda la documentación incluida en su proposición, cuestión ésta del todo improcedente, corresponderá al órgano de contratación, al objeto de dar cumplimiento al principio de publicidad y transparencia consagrado en la $\operatorname{LCSP}^{52}$ (ahora TRLCSP) y así motivar suficientemente la adjudicación, determinar aquella documentación de la proposición de la empresa adjudicataria que, en particular, no afecta a secretos técnicos o comerciales o no se corresponde con aspectos confidenciales, siendo necesario que se justifique debidamente en el expediente, y en su caso a la propia UTE recurrente -de solicitarlo expresamente la misma-, las causas que determinan el carácter confidencial de la citada documentación, sin que como consecuencia de ello pueda resultar la motivación de la adjudicación insuficiente a los efectos de interponer recurso especial suficientemente fundado".

\footnotetext{
${ }^{51}$ Ahora Art. 133 de la LCSP.

${ }^{52}$ Se refiere a la Ley 30/2007, de 30 de octubre, de Contratos del Sector Público.
} 
En el presente caso no se ha declarado la confidencialidad de toda la documentación relativa a la justificación de la baja económica anormal presentada por $\mathrm{CR}$, sino únicamente sobre algunos aspectos de la misma.

Es cierto que el órgano de contratación ha determinado, en la resolución recurrida, que la confidencialidad afecta a algunos aspectos adicionales a los expresamente declarados por $\mathrm{CR}$, por entender que guardaban relación con la documentación expresamente declarada confidencial por dicho licitador.

A pesar de que esta forma de actuar no es habitual, este Tribunal entiende que está amparada por lo previsto en el Art. 153 del TRLCSP, norma aplicable al caso en función de la fecha de publicación de la convocatoria del procedimiento (Disposición Transitoria Primera.1 de la LCSP). Dice este artículo que "el órgano de contratación podrá no comunicar determinados datos relativos a la adjudicación cuando considere, justificándolo debidamente en el expediente, que la divulgación de esa información puede obstaculizar la aplicación de una norma, resultar contraria al interés público o perjudicar intereses comerciales legítimos de empresas públicas o privadas o la competencia leal entre ellas".

Lo que ha sucedido es que, aunque formalmente parece que el órgano de contratación amplía los apartados de la justificación de la oferta de CR que ésta declara confidenciales, materialmente no es así, ya que realmente lo que hace es confirmar el carácter confidencial que a lo largo de su justificación atribuye dicha entidad licitadora a los datos que aporta, todos los cuales se conectan, integran o pertenecen al grupo o tienen la naturaleza de los que expresamente declara confidenciales en el apartado $4 \mathrm{y}$ en el anexo documental de su justificación.

La resolución recurrida motiva la extensión de la confidencialidad en la búsqueda del equilibrio entre la transparencia del procedimiento, y el derecho de protección de los intereses comerciales de las empresas, y en el Art. 153 del TRLCSP, los Arts. 12 y 14 de la Ley 2/2015, de Transparencia, Buen Gobierno y Participación Ciudadana de la Comunidad Valenciana, y en la Resolución nº91/2015 de este TACRC.

También alega la empresa recurrente la supuesta inviabilidad de la oferta de $\mathrm{CR}$, cuyo juicio hace descansar en la afirmación de que el precio ofertado no permite cubrir los costes laborales inherentes a la plantilla por aquélla ofertada.

En relación con este tema, el texto refundido de la Ley de Contratos del Sector Público (R.D. Legislativo 3/2011) aplicable al caso, a diferencia de la vigente Ley 9/2017, de Contratos del Sector Público, en sus Arts. 102.3 y 149.4, no exigía expresamente rechazar las ofertas incursas en presunción de anormalidad $o$ desproporción porque las mismas sean insuficientes para atender al cumplimiento de los convenios colectivos sectoriales.

\section{SUBSANACIÓN EN FASE DE REQUERIMIENTO}

En cuanto al fondo del asunto, en la resolución analizada ${ }^{53}$, la recurrente alega su oposición a la posibilidad de subsanar la documentación que debe presentar el

\footnotetext{
${ }^{53}$ Resolución nº38/2019 del Tribunal Administrativo de Recursos Contractuales de Castilla y León, de 4 de abril.
} 
propuesto como adjudicatario del contrato, al considerar que procede entender que ha retirado su oferta.

El Art. 150 de la LCSP nada indica sobre la posibilidad de subsanación de la documentación ${ }^{54}$, no obstante, hay que tener en cuenta que siempre se ha partido de una consideración favorable sobre la posibilidad de subsanación de los defectos formales relativos a la documentación acreditativa del cumplimiento de los requisitos previos de los licitadores y de las ofertas, con la finalidad de no limitar, con un excesivo rigorismo formal, la concurrencia de licitadores, sin que se pueda obviar que, de conformidad con lo indicado en el Art. 1 de la LCSP y sin perjuicio del necesario respeto al principio de igualdad, el procedimiento licitatorio debe ir encaminado a la selección de la oferta económicamente más ventajosa.

La Resolución $n^{\circ} 747 / 2018$ del TACRC, de 31 de julio, realiza un análisis exhaustivo de la cuestión indicando, entre otras circunstancias:

"1.- En primer lugar, no tiene sentido que tras un relativamente largo y costoso procedimiento para elegir al licitador que ha realizado la oferta económicamente más ventajosa, se le rechace de plano por existir algún error en la documentación presentada para poder realizar la adjudicación a su favor. Esta forma de actuar va en contra del interés general, que debe guiar siempre la forma de actuar de la Administración y con arreglo al cual deben interpretarse las leyes (artículo 103.1 de la Constitución). Recordemos que con la generalización y obligatoriedad del DEUC, prácticamente toda la documentación relativa a la empresa se presenta en esta fase del procedimiento (escrituras de constitución, de representación, documentos de identidad, solvencia económica, solvencia técnica, etc...), que, además, en el caso de que el licitador propuesto como adjudicatario sea una Unión Temporal de Empresas, como en el supuesto que nos ocupa, dicha documentación se multiplica por dos, tres o más.

\footnotetext{
${ }^{54}$ El Informe de la Junta Consultiva de la Comunidad de Madrid 4/2018, de 26 de julio, sobre posibilidad de subsanación de la documentación requerida al licitador que haya presentado la mejor oferta, considera que en esta cuestión debe tenerse presente la posibilidad de aplicación analógica de la subsanación que se prevé en el artículo 141.2 de la LCSP, respecto de la declaración responsable y la documentación a la que se refiere el artículo anterior, y de la aplicación supletoria prevista en la disposición final cuarta de la LCSP, de la Ley 39/2015, de 1 de octubre, del Procedimiento Administrativo Común de las Administraciones Públicas, cuyo artículo 73.2 determina la posibilidad de subsanación de la documentación presentada en cualquier procedimiento administrativo. La Resolución 321/2018, del Tribunal Administrativo de Contratación Pública de la Comunidad de Madrid, pone de manifiesto que "esta aplicación supletoria de la LPACAP al procedimiento de contratación es unánimemente admitida por la doctrina (...)".

En este sentido, el meritado Informe de la Junta Consultiva de la Comunidad de Madrid 4/2018, de 26 de julio, declara que: " $\mathrm{Si}$, entre la documentación presentada, se observasen defectos subsanables, que se refieran a la acreditación del requisito de que se trate, pero no a su cumplimiento, por analogía con lo previsto en el artículo 141.2 y, en todo caso, al amparo de lo dispuesto en el artículo 73.2 de la Ley $39 / 2015$, de 1 de octubre, (...), y dado que el licitador propuesto como adjudicatario ha cumplido con lo dispuesto en el artículo 150.2 de la LCSP y ha demostrado su voluntad de aportar la documentación requerida en plazo y mantener, por ello, su oferta, resulta adecuado y conveniente para el interés público otorgarle plazo para corregir los defectos u errores que la documentación aportada pueda presentar, o solicitarle las aclaraciones oportunas al respecto, teniendo en cuenta asimismo la jurisprudencia contraria al rigorismo formalista".
} 
El error es consustancial al ser humano, y resulta claramente desproporcionado rechazar de plano la mejor oferta seleccionada por no haber presentado perfectamente, en un primer momento, la numerosa documentación exigida.

2.- El artículo 150.2 de la nueva Ley 9/2017, de Contratos del Sector Público, establece en relación con este trámite, que "de no cumplimentarse adecuadamente el requerimiento en el plazo señalado, se entenderá que el licitador ha retirado su oferta, procediendo a exigirle el importe del 3 por ciento del presupuesto base de licitación, IVA excluido, en concepto de penalidad". Por tanto, con la nueva LCSP el licitador que fracasa en este trámite no sólo pierde la posibilidad de que se le adjudique el contrato (siendo la empresa mejor valorada), sino que además se le puede imponer una penalidad del 3\% del presupuesto base de licitación (entiende este Tribunal que la penalidad sólo procede cuando el incumplimiento de los requisitos para ser adjudicatario es grave y claro, y el licitador no ha actuado de buena fe y media dolo, culpa o negligencia).

La existencia de esta penalidad hace necesario, más que nunca, que se conceda al licitador propuesto como adjudicatario la posibilidad de subsanar los errores cometidos al presentar su documentación.

3.- (...) El artículo 151.2 del TRLCSP (así como el artículo 150.2 de la LCSP) establecen para el trámite que nos ocupa un plazo de diez días hábiles, sin hacer referencia a la posibilidad de subsanación y sin prohibirla o excluirla ${ }^{55}$.

En el ámbito de la contratación pública, el RGLCSP, en su artículo 81, y la LCSP, en el artículo 141.2 párrafo segundo, tiene una regulación especial sobre el plazo de subsanación, que lo fija en tres días hábiles.

4.- Las Leyes de Contratos siempre han establecido la subsanabilidad de la documentación administrativa presentada en el sobre número 1. En la actualidad, una vez establecida la obligatoriedad del DEUC (artículo 140.1.a) de la LCSP) esta documentación ya no se presenta en dicho sobre, sino sólo por el licitador propuesto como adjudicatario. Por tanto, también ahora debe permitirse la subsanación.

5.- Admitir la subsanabilidad de la documentación presentada por el licitador propuesto como adjudicatario no se considera que infrinja el principio de igualdad entre licitadores (...)". En este mismo sentido se pronunciaba con anterioridad el Tribunal Administrativo Central de Recursos Contractuales en la Resolución 338/2018 ${ }^{56}$.

\section{CONCLUSIONES}

\footnotetext{
55 Por tanto, esta regulación debe ser colmada, conforme a la mencionada disposición final tercera del TRLCSP, por la Ley 39/2015, cuyo Art. 73.2 dispone que: "en cualquier momento del procedimiento, cuando la Administración considere que alguno de los actos de los interesados no reúne los requisitos necesarios, lo pondrá en conocimiento de su autor, concediéndole un plazo de diez días para cumplimentarlo".

${ }^{56}$ En la que ponía de manifiesto que: “(...) tal posibilidad no pugna ni contradice lo determinado en el artículo 151.2 del TRLCSP, en cuanto que ese precepto solo se ha de aplicar a los casos en que efectivamente exista un incumplimiento efectivo y real del requerimiento o exista una conducta contumaz de incumplimiento de la subsanación de los defectos formales observados, pues solo en esos casos puede estimarse y afirmarse que el licitador ha retirado su oferta (...)". En virtud de todo lo expuesto, no cabe sino desestimar el recurso especial interpuesto.
} 
De las cuestiones analizadas cabe resaltar lo siguiente:

La doctrina de los Tribunales Administrativos de Contratación ha ido perfilando, en materia de teleasistencia, aspectos sustanciales para la adecuada definición del objeto, presupuesto base de licitación, prescripciones técnicas, así como cuestiones relativas a la subrogación o a la confidencialidad de las ofertas e información a licitadores.

Así, ha sido un criterio unánime de los Tribunales de contratación que la condición de arraigo territorial no pueda ser exigida como requisito de solvencia ni como criterio de adjudicación, sin embargo, como condición de ejecución se ha admitido en determinadas ocasiones.

En cuanto a los criterios de adjudicación, se admite valorar una mayor disponibilidad de centrales de respaldo a lo largo del territorio nacional, pues permite, ante circunstancias excepcionales, que las diversas centrales puedan hacerse cargo del servicio para diversas localidades, asegurando así la prestación del servicio ante cualquier tipo de eventualidad.

Respecto a la necesidad de establecer un límite máximo del número de centrales de respaldo, se ha considerado que ha de ser estimada esta pretensión, toda vez que no se trata de una prestación que se vaya a realizar en todo caso, sino únicamente ante "circunstancias excepcionales", que podrían no llegar a producirse. Incluso de tener lugar alguna eventualidad, podría suceder que no se necesitaran todas las centrales de respaldo indicadas, sino solamente una o algunas.

En relación con el criterio de valoración del número de vehículos a ofertar, se ha reseñado que se establezca un límite máximo al número de vehículos a ofertar, por encima del cual la Administración considere que no le reportará beneficio alguno el hecho de que el licitador cuente con una mayor flota de vehículos adicionales disponibles.

En lo que se refiere a la valoración de cursos de formación, se ha considerado que el criterio sí está vinculado al objeto del contrato, ya que puede redundar en una mejor prestación del servicio, en la medida en que se interprete que los cursos establecidos en el Plan de formación, independientemente de que se impartan a trabajadores de la empresa de otros centros de trabajo, se dirijan necesariamente a los trabajadores que van a efectuar la prestación objeto del contrato.

En el presupuesto base de licitación deberán consignarse los costes directos e indirectos y otros eventuales gastos, así como los costes salariales estimados a partir del convenio laboral sectorial, de forma desglosada y con desagregación de género y categoría profesional. Para el cálculo del valor estimado deberá observarse adecuadamente lo previsto en el Art. 101.2 de la LCSP.

Por lo que respecta a la subrogación de trabajadores, en el convenio colectivo se recogen de forma expresa e inequívoca la obligación de subrogación de los trabajadores de la adjudicataria saliente, y con una mención específica en relación a las empresas dedicadas al servicio de teleasistencia, en los términos que se recogen en los correspondientes artículos del convenio De su lectura se desprende que existe una 
obligación de subrogación de los trabajadores que se corresponde con la prevista en el pliego.

En lo concerniente a la posibilidad de declarar aspectos confidenciales en relación con las justificaciones de bajas, se admite la posibilidad de declararlas confidenciales.

\section{BIBLIOGRAFÍA}

- AA.VV., GIMENO FELIÚ, J.M. (Dir.), Estudio Sistemático de la Ley de Contratos del Sector Público, Thomson Reuters Aranzadi, 2018.

- AAVV., GUTIÉRREZ COLOMINA, V. (Dir.), Comentarios de la Ley de Contratos del Sector Público Por la que se transponen al ordenamiento jurídico español las Directivas del Parlamento Europeo y del Consejo 2014/23/UE y 2014/24/UE, de 26 de

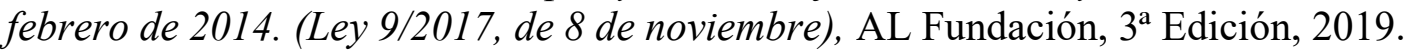

- CANAles GIL, Á., HUERTA BARAJAS, J. A., Comentarios a la Ley 9/2017 de Contratos del Sector Público, Estudios Jurídicos, BOE, 2018.

- GAMERO CASADO, E., GALLEGO CÓRCOLES, I. (Dirs), Tratado de contratos del sector público, Tirant lo Blanch, 2018.

- GIMENO FELIÚ, J.M., La Ley de Contratos de Sector Público 9/2017. Sus principales novedades, los problemas interpretativos y las posibles soluciones, Aranzadi, 2019.

- MESTRE DELGADO, J.F., MANENT ALONSO, L. (Dirs.), TENHAEFF LACKSCHEWITZ, S. (Coord.), La Ley de contratos del sector público: Ley 9/2017, de 8 de noviembre. Aspectos novedosos, Tirant lo Blanch, 2018.

- MORENO MOLINA, J.A., El nuevo Derecho de la contratación pública de la Unión Europea Directivas 4.0, Chartrige Books Oxford, 2015.

- MORENO MOLINA, J.A., Hacia una Compra Pública Responsable y Sostenible. Novedades principales de la Ley de contratos del sector público 9/2017, Tirant lo Blanch, 2018.

- PAlOMAR OLMEDA, A., GARCÉS SANAGUSTín, M. (Dirs.), VÁZQUEZ GARRANZO, J. (Coord.), Comentarios a la Ley de Contratos del Sector Público, La Ley, Wolters Kluwer, 2018.

- RODRÍGUEZ-ARANA MUÑOZ, J., "Los principios generales de la contratación pública global (Especial referencia al Derecho Comunitario Europeo)", en AA.VV., Bases y retos de la contratación pública en el escenario global "Actas del XVI Foro Iberoamericano de Derecho Administrativo" Santo Domingo, 02 y 03 de octubre de 2017, Editorial Jurídica Venezolana, 2017. 